\title{
Offshoring in a Ricardian World
}

\author{
By Andrés RodríGUEZ-Clare*
}

\begin{abstract}
This paper proposes a Ricardian model to understand the short-run and long-run aggregate effects of increased fragmentation and offshoring on rich and poor countries. The short-run analysis shows that, when offshoring is sufficiently high, further increases in offshoring benefit the poor country and hurt the rich country. But these effects may be reversed in the long run as countries adjust their research efforts in response to increased offshoring. In particular, in the long run, the rich country always gains from increased offshoring, whereas poor countries see their static gains partially eroded by a decline in their research efforts. (JEL F12, F23, L24, M16)
\end{abstract}

$\mathrm{T}$ echnological change has led to a dramatic decline in the cost of communication and in the cost of coordinating activities performed in different locations. This has allowed firms in rich countries to fragment their production process and offshore an increasing share of the value chain to low-wage countries!, 1,2 Richard Baldwin (2006) refers to this phenomenon as the "second unbundling." In his words,

"rapidly falling transportation costs caused the first unbundling, namely the end of the necessity of making goods close to the point of consumption. More recently, rapidly falling communication and coordination costs have fostered a second unbundling - the end of the need to perform most manufacturing stages near each other. Even more recently, the second unbundling has spread from factories to offices with the result being the offshoring of service-sector jobs." (Baldwin 2006, 7).

The purpose of this paper is to explore the welfare consequences of this phemonenon. There has been much discussion recently about this with a specific focus on the impact of offshoring on rich countries. Two popular approaches can be clearly

\footnotetext{
* Pennsylvania State University, 608 Kern Graduate Building, University Park, PA 16803 (e-mail: andres@ psu.edu) and National Bureau of Economic Research. I thank seminar participants at Fundacao Getulio Vargas, Pennsylvania State University, Princeton University, Wesleyan University, South Methodist University, Rochester University, Dartmouth University, and the Spring Meeting of the International Trade and Investment Program of the NBER for helpful comments, as well as Kei-Mu Yi, Jim Tybout, Barry Ickes, Andrew Bernard, Doug Irwin, Matt Slaughter, Alan Deardorff, and Manolis Galenianos for useful suggestions. I am deeply grateful to Alexander Tarasov for outstanding research assistance.

${ }^{\dagger}$ To comment on this article in the online discussion forum, or to view additional materials, visit the articles page at http://www.aeaweb.org/articles.php?doi=10.1257/mac.2.2.227.

${ }^{1}$ Ronald W. Jones and Henryk Kierzkowski (1990) proposed this way of thinking about technological change, fragmentation, and international trade. Kei-Mu Yi (2003) develops a Ricardian model of trade to show that trade liberalization may also lead to increased fragmentation (or what he calls vertical specialization) and trade.

${ }^{2}$ See Alan S. Blinder (2006), Gregory N. Mankiw and Phillip Swagel (2006), Gene M. Grossman and Esteban Rossi-Hansberg (2006), for an analysis of the US data showing that offshoring has grown dramatically over the last years.
} 
distinguished. They both start from the notion that the unbundling of the production process entails an expansion of the set of tradeable goods and services, but go on to explore different implications. The first approach starts from the premise that trade entails gains for all parties involved, and then concludes that fragmentation and offshoring should be good for all countries. As Mankiw argued during a press conference in 2004: "More things are tradable than were tradable in the past, and that's a good thing" (Mankiw and Swagel 2006, 9). In contrast, the second approach reasons that increased fragmentation possibilities and lower trade costs in the limit would allow the world to reach an "integrated equilibrium" in which wages for identical workers in different countries would necessarily be equalized. In other words, wages would no longer be affected by the location of workers. For example, in their recent book on offshoring, Ron Hira and Anil Hira (2005) argue that offshoring affects American workers by undermining their "primary competitive advantage over foreign workers: their physical presence in the US." Other noneconomists writing about offshoring have expressed similar concerns 3

A simple "toy" model may be useful to understand these two approaches to offshoring. First, consider a two-country model with labor as the only factor of production, and one final good. For concreteness, let us think of the two countries as the United States (US) and the rest of the world (RW), and assume that the US has higher productivity, which entails higher wages. The existence of a single tradable good implies that there is no trade. But assume that fragmentation becomes feasible, so that some labor services can now be unbundled from the production of the final good. If the productivity in these labor services is the same across the two countries, then trade arises, with the US specializing in the production of the final good in exchange for labor services imported from the RW via offshoring operations. It is clear that both countries gain from the new trade made possible by fragmentation, just as in the first of the two approaches discussed above.

Imagine now that there are two final goods that can be traded at no cost between the US and the RW. Further assume that the US has a higher productivity in good 1 , while productivities are the same in good 2. If the US is not too large relative to the world's demand for good 1, then it will specialize completely in that good and enjoy gains from trade that allow it to sustain higher wages than in the RW. As fragmentation becomes possible, US firms will engage in offshoring to use labor in the RW for part of their production process in good 1 . This will effectively enlarge the US supply of good 1, which will worsen its terms of trade (hereafter TOT). If this process is sufficiently strong, the international relative price of good 1 will converge to the US opportunity cost of this good, at which point the US will no longer benefit from trade, and its wage level will become equal to that in the RW ${ }^{4}$ This captures the concerns of the second approach to offshoring mentioned earlier.

Each of these examples highlights an important aspect of the offshoring phenomenon. Fragmentation leads to new trade and to an expansion in the supply of the good in which the advanced country has a comparative advantage. From the point

\footnotetext{
${ }^{3}$ See Paul Craig Roberts (2004) and Thomas L. Friedman (2005).

${ }^{4}$ This effect of fragmentation and offshoring on the rich country is discussed in Alan V. Deardorff (2001) and in Edward E. Leamer (2007).
} 
of view of the advanced country, the first effect is positive, while the second effect is negative. What is the net effect? To answer this question, one needs to consider a general trade model that is able to capture the roles played by both absolute and comparative advantage. The presence of an overall absolute advantage in the advanced country is a key element, as this is what leads to the wage gap that generates incentives for offshoring. Comparative advantage is also clearly necessary, as this is what gives rise to trade in the absence of fragmentation, which is required for the negative TOT effect to arise. A general yet parsimonious model in which both absolute and comparative advantage play a role in determining wages and the gains from trade is Jonathan Eaton and Samuel Kortum's (2002) model of Ricardian trade. In this paper, I start out with this model, and then allow for fragmentation and offshoring to explore their impact on wages in advanced and poor countries. 5

Eaton and Kortum model sector-level productivities as being drawn from a distribution that is common across countries except for a technology parameter $T$. This technology parameter determines the location of the productivity distribution. Countries with a higher $T$ have "better" distributions in the sense of first-order stochastic dominance. Apart from $T$, countries also differ in $L$, the size of their labor force (which is the only factor of production). Assuming away trading costs for simplicity, wages are determined by the ratio of technology to size, $T / L$. A high $T / L$ means that the country would have many sectors in which it has absolute advantage relative to its size, leading to a high equilibrium wage. It is interesting to note that, given a fixed technology level, an increase in a country's labor force-caused, perhaps, by immigration-would lead to a decline in $T / L$, and hence a decline in the country's wage. This is nothing but the classic effect of size on a country's TOT in a Ricardian model 6

Fragmentation is introduced into the model by assuming that production involves the combination of a continuum of labor services, a share of which may be offshored at no cost and with no loss of productivity. ${ }^{7}$ Thus, fragmentation leads firms in highwage countries (i.e., countries with a high $T / L$ ) to offshore a part of their production process to low-wage countries. This represents new trade, where high $T / L$ countries export final goods in exchange for imports of labor services through offshoring.

This model provides a simple way to study the impact of fragmentation and offshoring on wages in both rich and poor countries. Both effects mentioned above are present. There are gains from the new trade that takes place, as well as a movement toward wage equalization that harms the rich countries and benefits the poor countries. The first is a productivity effect. It captures the idea that firms experience a decline in their unit costs as they offshore part of their production to low-wage

\footnotetext{
${ }^{5}$ I focus entirely on the impact of offshoring on average wages rather than on the wage distribution or skill premia. In other words, I am interested in understanding the conditions under which the winners from offshoring can compensate the losers, but do not consider the differential impacts on workers with different skill levels or in different activities or industries. Readers interested in this issue can consult Robert C. Feenstra and Gordon H. Hanson (1996, 1999), Jones and Kierzkowski (2001), Deardorff (2004), James Markusen (2005), Blinder (2006), and Grossman and Rossi-Hansberg (2006, 2008), among others.

${ }^{6}$ See Don R. Davis and David E. Weinstein (2002) for a recent discussion of the economic impact of immigration in the United States using this basic idea.

${ }^{7}$ The modelling of offshoring as trade in a continuum of labor services is similar to the approach in Grossman and Rossi-Hansberg (2008), see below.
} 
countries. The second is a terms of trade effect. Finally, this analysis also reveals the existence of a world-efficiency effect, often neglected in discussions of offshoring, which entails a decline in world prices as labor is effectively reallocated from countries with low to countries with high $T / L$ ratios.

From the point of view of poor countries, only the TOT and world efficiency effects are present, and both are positive, so these countries always benefit from fragmentation. But rich countries have to deal with the negative TOT effect. The analysis reveals that there is always a point beyond which increased fragmentation leads to a negative effect on the real wage in the rich country. In other words, when fragmentation is already high, a further increase in fragmentation generates a negative TOT effect that dominates the productivity and world-efficiency effects. ${ }^{8}$ More specifically, if the technology gap between rich and poor countries is not too low, then the real wage in rich countries as a function of the level of fragmentation is shaped like an inverted $U$. Initially fragmentation leads to a higher real wage, but this is eventually reversed as fragmentation becomes sufficiently high. In the limit, as we approach a world with complete fragmentation and wage equalization, the real wage in the rich country must necessarily be lower than it would be under no fragmentation.

The result that in rich countries the positive productivity effect of offshoring can be dominated by a negative TOT effect, is reminiscent of the possibility of "immiserizing growth" for large countries analyzed by Bhagwati (1958). This suggests that in the presence of an optimal tariff or export tax, increased fragmentation would always improve welfare in the rich country. I show that this is indeed the case (at least for a "small economy" for which this can be done analytically).

The discussion of fragmentation and wages so far takes technology levels as exogenous, and can be interpreted as a short-run analysis. But, in the long run, technology levels are endogenous, determined by research efforts and research productivity. It is conceivable that the resources released by offshoring in the rich countries lead to an increased allocation of resources to research. This would tend to increase the $T / L$ ratio and provides a new positive effect on wages not present in the static analysis.

To explore this possibility, I consider a dynamic model in which technology levels are endogenous, as in Eaton and Kortum (2001). In this dynamic model, workers choose to work in the production sector or to do research, which leads to new ideas or technologies. When the technology discovered is superior to the state of the art, its owner (or patent holder) earns quasi-rents that provide a return on the opportunity cost of research. The technology parameter $T$ can now be interpreted as the "stock of ideas" in a country, and richer countries are the ones that have a higher stock of ideas per worker. Without fragmentation, the fraction of workers devoted to research turns out to be the same across countries, but countries with a higher research productivity (i.e., a higher rate of arrival of ideas per researcher) can sustain a higher $T / L$, and hence higher wages in steady state. Fragmentation generates the same short-run effects as above, but now we must also take into account the impact on the allocation

\footnotetext{
${ }^{8}$ Although clearly related, this is not a simple application of the immiserizing growth possibility studied by Jagdish Bhagwati (1958). In fact, as discussed in footnote 13, although higher efficiency in the Eaton and Kortum (2002) model leads to declining terms of trade, this would never dominate the direct benefits.
} 
of workers between production and research in both the rich and poor countries. It will be shown that fragmentation and offshoring induce more people in rich countries to work as researchers, which in the long run increases $T / L$ and wages, counteracting the negative effects mentioned above. In fact, the analysis reveals that in steady state this research effect weakens the TOT effect to such an extent that it is now always dominated by the productivity effect. The result is that, in the long run, wages in rich countries always increase with fragmentation.

The long-run effects of fragmentation turn out to be quite different in poor countries. There, as people start to work as providers of labor services through offshoring operations, the fraction of people devoted to research falls, decreasing $T / L$ and wages. This entails a negative research effect that in steady state exactly compensates the positive TOT effect. Thus, just like every other country (even the ones that do not participate in offshoring activities), poor countries benefit from fragmentation only through the world-efficiency effect.

In sum, the analysis suggests that increased fragmentation could have negative effects for rich countries, but that these effects dissipate in time, so that the long run effects are always positive for the countries doing the offshoring. In contrast, the long-run effects of fragmentation in poor countries are weaker than the corresponding short-run effects. For the rich country, the presence of opposite short- and longrun effects implies that increased fragmentation could be harmful or beneficial. For a special case that can be analytically solved, I show that as long as the speed with which resources can be reallocated across production and research is sufficiently high, then the long-run effects dominate, and the rich country gains from offshoring.

In thinking about the connection between innovation and offshoring, I follow a long tradition in the literature by focusing on the implications of trade for the allocation of resources to innovation (see Grossman and Elhanan Helpman 1991). This leaves out some possibly relevant channels. First, as shown by Alireza Naghavi and Gianmarco Ottaviano (2009), offshoring can decrease research effectiveness and growth in the north by weakening the information feedback from production to R\&D? In contrast, offshoring can lead to knowledge spillovers that benefit the poor country. Second, innovation could be directed at expanding the range of tasks that can be offshored. If such innovation is carried out by the poor country (e.g., India develops technology that allows it to provide IT support to companies in the US), then that country would benefit more than is implied by the model developed here, where the range of tasks that can be offshored is taken to increase exogenously. Finally, innovation can be seen as a set of activities that are also amenable to offshoring. In fact, some authors have noted, with some concern, that this is already taking place in the US (Dieter Ernst 2006, and Jeffrey T. Macher and David C. Mowery 2008). A limitation of the present model is that this type of offshoring does not take place since the north does not want to offshore research to the south. In the conclusion, I briefly touch on some of these issues, but a full exploration is left for future research.

\footnotetext{
${ }^{9}$ Brian J. Fifarek, Francisco M. Veloso, and Cliff I. Davidson (2008) argue that this negative effect of offshoring on innovation has already taken place in the rare earth element industry in the United States.
} 
There is a long list of recent papers that have analyzed the possible effects of fragmentation and offshoring on wages in rich countries. .10 Paul A. Samuelson (2004) stressed the possible negative impact of offshoring if it leads to spillovers that erode the rich countries' technological advantage in exporting sectors, while Deardorff (2001, 2005) showed that, even without such spillovers, rich countries would suffer a deterioration of their TOT that could more than compensate any associated gains. Bhagwati, Arvind Panagariya, and T. N. Srinivasan (2004) and Mankiw and Swagel (2006) argued that the negative TOT effect would likely be dominated by the positive productivity effect. The present paper shows that in the short run this is not necessarily the case. In fact, when fragmentation is sufficiently high, further increases in fragmentation (and offshoring) necessarily hurt the rich country. But, again, this applies only in the short run. In the long run, when research efforts have had time to fully adjust to the new environment, rich countries are always better off with offshoring than without.

Another group of papers have explored the implications of fragmentation on wages for skilled and unskilled workers in the context of a Hecksher-Ohlin model of trade.11 Prominent examples are Feenstra and Hanson (1996), Jones and Kierzkowski (2001), Deardorff (2004), Kohler (2004), Markusen (2005), Grossman and Rossi-Hansberg (2006, 2008), and Baldwin and Frédéric Robert-Nicoud (2007). The contribution of Grossman and Rossi-Hansberg (2008); or GRH, is particularly relevant to the present paper. In their main specification, fragmentation is seen as the decline in the cost of trading a continuum of unskilled tasks. Focusing on a skilled-labor abundant country, GRH show that fragmentation leads to increased offshoring of such tasks, a positive productivity effect that increases the wage of unskilled workers, and an improvement in the TOT that has the usual Stolper-Samuelson implications. In another specification, GRH explore the consequences of an overall decline in the costs of offshoring all tasks (skilled and unskilled). GRH note that this generates a positive productivity effect, but a deterioration of the country's TOT. Offshoring also has these conflicting effects on the rich country in the Ricardian model presented below, but the model has the advantage that these two effects can be compared in such a way that the net result can be fully characterized both in the short run and in the long run.

The connection between offshoring and innovation has received scant attention in the literature. Two exceptions are Amy Jocelyn Glass and Kamal Saggi (2001) and Naghavi and Ottaviano (2009). Glass and Saggi (2001) extend Grossman and Helpman's (1991) quality-ladder growth model to a two-country setting with offshoring. Focusing on the steady state, they show that a decline in the cost of offshoring leads to an increase in innovation in the rich country and an increase in the growth rate. However, in their model, the increase in innovation must be accompanied by

\footnotetext{
${ }^{10}$ For recent surveys see Mankiw and Swagel (2006) and Baldwin (2006). See also Martin Neil Baily and Robert Z. Lawrence (2004) for an exploration of the implications of offshoring for the loss of manufacturing jobs in the US over the last decades. For an analysis of the effect of offshoring on unemployment see Devashish Mitra and Priya Ranjan (2009).

${ }^{11}$ Another approach is Willhelm Kohler (2004), who explores the consequences of offshoring in a specificfactors model of a small-open economy, and shows conditions under which the presence of nonconvexities may lead offshoring to harm the rich country.
} 
a decline in the rich country's wage to keep innovation profitable. In contrast, I build on the quasi-endogenous growth framework of Kortum (1997) and Eaton and Kortum (2001), so offshoring has no growth effects, and the steady state effect on the rich country's wage is positive thanks to the direct productivity effect and the long-run effect of increased research on the rich country's technology distribution.

Finally, Robert-Nicoud (2008) explores the effect of offshoring in a New Economic Geography model a la Paul R. Krugman and Anthony J. Venables (1995), where "manufacturing" is subject to economies of agglomeration, while agriculture is produced with aggregate constant returns to scale. Robert-Nicoud shows that fragmentation and offshoring enlarges the set of parameters for which there is an equilibrum with manufacturing concentrated in the north. The conclusion is that offshoring helps the north to counteract the deindustrialization forces unleashed by a decline in the cost of trading manufacturing goods.

The rest of the paper is organized as follows. Section I introduces the static model and derives the implications of fragmentation on both rich and poor countries participating in offshoring activities. Section II presents a dynamic model where technology levels are endogenously determined by research efforts in each country. In the short run, this model is equivalent to the static model of Section I. I use this model to explore the implications of fragmentation on long-run (steady-state) research intensities and wages in the rich and poor countries participating in offshoring. I also study the transition dynamics to understand the net welfare effects of an unexpected increase in fragmentation. Section III compares the implications of offshoring to immigration, and Section IV presents an extension of the model. Section V concludes. All proofs are relegated to a Web Appendix.

\section{The Static Model}

The static model builds on the Eaton and Kortum (2002) model of Ricardian trade under the simplifying assumption of no transportation costs. There are $N$ countries, indexed by $i \in\{1,2, \ldots, N\}$, and a continuum of tradable final goods, indexed by $j \in[0,1]$. Labor is the only factor of production, and is supplied inelastically at quantity measure $L_{i}$ in country $i$. Preferences across goods are Cobb-Douglas and symmetric, so that an equal share of income is spent on each good $j$.

All final goods are produced from a single "common input" for which the cost in country $i$ is denoted by $c_{i}$. In a standard Ricardian model, the common input is labor, so $c_{i}$ is simply the wage $w_{i}$. Here, I allow for a more general production structure to introduce fragmentation and offshoring into the model, so $c_{i}$ may differ from $w_{i}$. In particular, I assume that the common input is produced through a Leontief production function from a continuum of intermediate services indexed by $k \in[0,1]$. Formally, letting $x(k)$ represent the quantity of intermediate service $k$, then output of the common input is $X=\min _{k}\{x(k)\}$. In turn, $x(k)$ is produced one-to-one from labor. If all intermediate services must be produced directly by the firm, then this collapses to the standard case with $c_{i}=w_{i}$. Fragmentation is introduced by allowing firms to costlessly offshore at most a certain exogenous share $\beta \in[0,1[$ of the intermediate services. The assumption that $\beta$ is exogenous simplifies the analysis considerably, but is not essential. As I show in Section IV, the main 
results go through in a setting where the measure of services that are offshored is endogenous to the costs of trading services as in Kohler (2004) and Grossman and Rossi-Hansberg (2006). Below, I refer to the restriction that firms cannot offshore more than a share $\beta$ of services as the "offshoring restriction."

To simplify the analysis and exposition, I focus on the possibility of offshoring by country 1 from country 2 (country 1 is the rich country), while offshoring is not possible for all the other countries. In Section IV, I extend the analysis to allow for offshoring between three countries. Except for that, all of the main results of the paper could be derived in a setting with only two countries, but I consider $N$ countries because this does not entail any complications (it actually makes the presentation simpler), and because this will be needed for some extensions that I discuss below.

If $w_{1}>w_{2}$, then firms in country 1 would want to exploit all opportunities for offshoring, and hence the unit cost of the common input there would be

$$
c_{1}=(1-\beta) w_{1}+\beta w_{2} .
$$

More generally, we have $c_{1}=\min \left\{w_{1},(1-\beta) w_{1}+\beta w_{2}\right\}$, while $c_{i}=w_{i}$ for $i \neq 1$.

The common input is converted into final goods through the use of linear technologies that vary in productivity across goods and countries. Letting $z_{i}(j)$ denote the productivity for good $j$ in country $i$, then country $i$ 's unit cost for $j$ is $c_{i} / z_{i}(j)$. These linear technologies are available to all firms within a country, so the appropriate market structure is perfect competition. Given the absence of transportation costs, then the price of good $j$ in all countries is simply $\min _{i}\left\{c_{i} / z_{i}(j)\right\}$.

As in Eaton and Kortum (2002), the productivities $z_{i}(j)$ are modelled as the realization of a random variable that is assumed to be independent across goods and countries. In particular, in country $i$, the productivity $z_{i}$ for each $\operatorname{good} j \in[0,1]$ is drawn from the Fréchet distribution,

$$
F_{i}(z)=\operatorname{Pr}\left[z_{i} \leq z\right]=\exp \left[-T_{i} z^{-\theta}\right]
$$

where $T_{i}>0$ and $\theta>1$. The parameter $T_{i}$ can vary across countries and determines the location of the distribution. A higher $T_{i}$ implies that the productivity draws are likely to be better. Thus, $T_{i}$ is country $i$ 's technology level and determines the share of goods in which it has absolute advantage relative to other countries across the continuum of goods. The parameter $\theta$ (which is common across countries) determines the variability of the draws, and hence the strength of comparative advantage. A lower $\theta$ implies a stronger comparative advantage.

\section{A. Equilibrium with No Offshoring}

To establish a benchmark, introduce some notation and develop some initial intuition for the results to come, consider first the case with no offshoring, or $\beta=0$. The unit cost of the common input in country $i$ is then simply $w_{i}$ (i.e., $c_{i}=w_{i}$ for all $i$ ). 
Given the preferences previously specified, the share of total income that each country spends on imports from country $i$ is equal to the share of goods for which country $i$ is the least-cost producer. In turn, this is equal to $\pi_{i}=T_{i} w_{i}^{-\theta} / \Phi$, where $\Phi \equiv \sum_{k} T_{k} w_{k}^{-\theta} 12$ Note that, given $w_{i}$, a higher $T_{i}$ implies more exports, and the same happens with a lower $w_{i}$ given $T_{i}$.

Wages are determined by the trade-balance conditions, which, in this context of no trade costs, are simply given by

$$
\pi_{i} Y=w_{i} L_{i},
$$

where $Y \equiv \sum_{k} w_{k} L_{k}$ is worldwide income. Using country $N$ 's labor as numeraire (i.e., $w_{N}=1$ ), it is easy to show that

$$
w_{i}=\delta\left(T_{i} / L_{i}\right)^{\kappa},
$$

where $\delta \equiv\left(T_{N} / L_{N}\right)^{-\kappa}$ and $\kappa \equiv 1 /(1+\theta)$. Note that an increase in size $L_{i}$, holding the technology level $T_{i}$ constant, implies a decline in country $i$ 's wage. This happens through a deterioration of country $i$ 's TOT and is the channel through which increased fragmentation and offshoring could lower country 1's income level 13

\section{B. Equilibrium with Offshoring}

Consider now the case in which offshoring is feasible $(\beta>0)$. The cost of the common input in country 1 will differ from the wage there because of the possibility of indirectly using labor at the cheaper cost $w_{2}$ in country 2 . In particular, if $w_{1}>w_{2}$, then the offshoring restriction will be binding, and $c_{1}$ will be given by (1). Moreover, since a share $1-\beta$ of the total quantity of the common input is produced domestically, then the full employment condition in country 1 entails $(1-\beta)$ $X=L_{1}$. The total amount of labor used in country 2 via offshoring, $\beta X$, is then equal to $\alpha L_{1}$, where $\alpha \equiv \beta /(1-\beta)$. (Even though $\alpha$ and $\beta$ capture the same thing, in the rest of the paper I will use both of these parameters, at each point choosing the one that helps to convey the results more clearly.) Since all countries other than 1 do not engage in offshoring, $c_{i}=w_{i}$ for all $i \neq 1$. The import shares in equilibrium are now

$$
\pi_{i}=T_{i} c_{i}^{-\theta} / \Phi
$$

\footnotetext{
12 To see this, note that the distribution of the price that country $i$ would charge for a particular good, $p_{i}=w_{i} / z$, is $\operatorname{Pr}_{i}\left(p_{i} \leq p\right)=\operatorname{Pr}_{i}\left(z \geq w_{i} / p\right)=G_{i}(p) \equiv 1-e^{-T_{i}\left(w_{i} / p\right)^{-\theta}}$. In turn, the distribution of the minimum price across countries $i \in \Gamma, p(\Gamma) \equiv \min _{i \in \Gamma}\left\{p_{i}\right\}$, is $G_{\Gamma}(p)=1-\prod_{i \in \Gamma} \operatorname{Pr}_{i}\left(p_{i} \geq p\right)=1-e^{-\Phi(\Gamma) p^{\theta}}$, where $\Phi(\Gamma)$ $\equiv \sum_{i \in \Gamma} T_{i} w_{i}^{-\theta}$. Hence, letting $\Gamma(-i)$ be the set of countries other than $i$, the probability that country $i$ has the lowest cost is $\pi_{i}=\int_{0}^{\infty} G_{\Gamma(-i)}(p) d G_{i}(p)=T_{i} w_{i}^{-\theta} / \Phi$.

${ }^{13}$ Note, however, that growth cannot be immiserizing in this case. Consider an increase in productivity that is manifested as an increase in "efficiency units" per person (an increase in $T$ would always lead to a higher wage). Total efficiency units are now $L=e N$, with $e$ being efficiency units per person, and $N$ being the level of population (or labor force). The wage is now $\delta e(T / e N)^{\kappa}$, which is increasing in $e$ given that $\kappa<1$.
} 
for all $i$. The trade balance conditions are unchanged for $i \neq 1,2$, whereas for countries 1 and 2, they are now given by

$$
\pi_{1} Y=w_{1} L_{1}+\alpha w_{2} L_{1}
$$

and

$$
\pi_{2} Y=w_{2} L_{2}-\alpha w_{2} L_{1} .
$$

The term $\alpha w_{2} L_{1}$ is simply the value of intermediate services imported by country 1 from country 2 .

Combining (5), for $i=2$, with (7) yields

$$
w_{2}=\delta\left(T_{2} / \tilde{L}_{2}\right)^{\kappa},
$$

where

$$
\tilde{L}_{2} \equiv L_{2}-\alpha L_{1}
$$

is the number of workers left in country 2 for production given that $\alpha L_{1}$ workers are devoted to offshoring services for country 1 . Comparing (4) and (8) shows that country 2's wage is increased by offshoring, i.e., $w_{2}^{\prime}(\alpha)>0$. The reason for this is that a decline in the number of workers left for production, given a fixed technology level, increases the ratio $T_{2} / \tilde{L}_{2}$, and thereby improves country 2's TOT. As intuition would suggest, the effect of offshoring on $w_{2}$ is exactly the same as the effect of a reduction in $L_{2}$ due to outmigration in country 2.

Turning to country 1 , combining equations (5), for $i=1$, with (6) implies that

$$
(1-\beta) w_{1}+\beta w_{2}=\delta\left(T_{1} / \tilde{L}_{1}\right)^{\kappa}
$$

where

$$
\tilde{L}_{1} \equiv(1+\alpha) L_{1}
$$

is the "effective" amount of labor devoted to production in country 1 , once we take into account the extra labor used through offshoring. Equation (10) shows that, given $w_{2}$, offshoring has two opposite effects on the wage in country 1 . First, there is an increase in the effective number of workers in production (i.e., $\tilde{L}_{1}>L_{1}$ ), which worsens its TOT. Second, there is a decline in costs thanks to the use of cheaper labor in country 2 through offshoring (i.e., $w_{2}<w_{1}$ ). Below I refer to these two effects as the terms of trade effect and the productivity effect. The net impact of these two effects on the equilibrium wage in country 1 is explored below. For now, the task is to fully characterize the equilibrium for all the relevant parameter values. 
Equations (8) through (11) determine the equilibrium wages in countries 1 and 2 if two constraints are satisfied. First, there is a resource constraint in country 2 , which implies that $\alpha L_{1} \leq L_{2}$. Second, wages satisfy $w_{1}>w_{2}$. This is equivalent to $T_{1} / \tilde{L}_{1}>T_{2} / \tilde{L}_{2}$. Letting $\eta \equiv\left(T_{1} / L_{1}\right) /\left(T_{2} / L_{2}\right)$, then this inequality can be written as

$$
\eta\left(1-\alpha L_{1} / L_{2}\right)>1+\alpha .
$$

From now on, I will assume that $\eta>1$. This is simply a condition that with no offshoring we have $w_{1}>w_{2}$. Given $\eta>1$, then the inequality in (12) is satisfied for $\alpha=0$. As $\alpha$ increases the LHS falls, whereas the RHS increases, and there is a level of $\alpha$ such that the two sides become equal, namely

$$
\bar{\alpha} \equiv \frac{\eta-1}{1+\eta L_{1} / L_{2}} .
$$

Thus, the inequality in (12) is satisfied if and only if $\alpha<\bar{\alpha}$. If this inequality is satisfied, then it is easy to check that the resource constraint in country 2 (i.e., $\alpha L_{1} \leq L_{2}$ ) is also satisfied. Thus, if $\alpha<\bar{\alpha}$, the equilibrium is characterized by the solution of equations (8) through (10).

What is the equilibrium if $\alpha \geq \bar{\alpha}$ ? In this case the equilibrium entails $w_{1}=w_{2}$, the offshoring restriction is not binding, and the equilibrium is characterized by the equations (8)-(10), but with $\bar{\alpha}$ rather than $\alpha$. It is important to note that if $\alpha \geq \bar{\alpha}$, then offshoring allows economies 1 and 2 to reach an integrated equilibrium, so factor price equalization (FPE) holds (i.e., $w_{1}=w_{2}$ ). In the rest of the paper, I refer to this case as "full offshoring."

\section{Wages under Full Offshoring}

Here, I compare the wage in country 1 under full offshoring with the level that prevails with no offshoring. In the subsections that follow, I turn to a more general comparative-statics analysis to understand the effect of fragmentation on wages in countries 1 and 2.

Since economies 1 and 2 are effectively integrated through offshoring, it is possible to consider them as if they were a single region in a world with no offshoring. To explore this further, I now use the index $m$ to refer to the region composed of countries 1 and 2. This region has workforce $L_{m} \equiv L_{1}+L_{2}$, and for each good it will use the best among the two technologies available, hence, for each $j$, we have $z_{m}(j)$ $=\max \left\{z_{1}(j), z_{2}(j)\right\}$. It is easy to verify that this implies that $z_{m}(j)$ is distributed Fréchet with parameters $\theta$ and $T_{m} \equiv T_{1}+T_{2}$. The share of world income spent on imports from region $m$ is given by

$$
\pi_{m}=\frac{T_{m} w_{m}^{-\theta}}{\Phi}
$$

where $\Phi=T_{m} w_{m}^{-\theta}+\Phi_{-m}$, and $\Phi_{-m} \equiv \sum_{k \neq 1,2} T_{k} w_{k}^{-\theta}$. Total income in region $m$ is $w_{m} L_{m}$, and the trade balance condition for this region is now simply $\pi_{m} Y=w_{m} L_{m}$. 
Just as in the case of no offshoring considered above, we now have

$$
w_{m}=\delta\left(T_{m} / L_{m}\right)^{\kappa}
$$

The effect of full offshoring on the wage in country 1 can now be determined by comparing $w_{1}$ under no offshoring with $w_{m}$. It is easy to see that since $\eta>1$, $T_{m} / L_{m}<T_{1} / L_{1}$, and $w_{m}<\left.w_{1}\right|_{\alpha=0}$. Intuitively, integration with country 2 through offshoring effectively lowers country 1's technology level per worker $(T / L)$, and this leads to a decline in its TOT.

This result concerns the effect of full offshoring on the wage in country 1 relative to the wage of the numeraire country. But it is also important to consider the impact on the real wage $w_{1} / P$, where $P$ is the price index of a unit of utility. It is straightforward to show that

$$
P=\tilde{\gamma} \Phi^{-1 / \theta},
$$

where $\tilde{\gamma} \equiv e^{-\gamma / \theta}$, and $\gamma$ is Euler's constant ${ }^{14}$ Since $\Phi=\sum_{k} T_{k} c_{k}^{-\theta}$, this expression implies that higher technology levels or lower unit costs lead to lower prices. From this expression it is now easy to establish that $P$ is lower under full offshoring than with no offshoring, 15 a result that reflects the higher efficiency attained when labor effectively reallocates from country 2 to country 1 . There are then two opposite effects on the real wage in country 1 as we move from no offshoring to full offshoring: the TOT effect, which decreases the relative wage $w_{1}$, and the world-efficiency effect, which lowers the price index $P$. Note that there is no productivity effect here because there is no longer a wage gap between countries 1 and 2 . As a consequence, country 1 does not gain from trading services with country $2{ }^{16}$ In other words, country 1's cost savings from using cheaper labor in country 2 are dissipated as more and more offshoring is undertaken by country 1's firms. This is similar to the result that a large economy gains nothing from trade when the international price becomes equal to its autarky price.

As shown in the Web Appendix, the TOT effect always dominates the worldefficiency effect, so that $w_{1} / P$ is necessarily lower under full offshoring than with no offshoring. Recalling that the wage in country 2 increases with offshoring, this result leads to the following proposition.

\footnotetext{
${ }^{14}$ To see this, note from footnote 12 that the distribution of the international price is $G_{\Gamma}(p)$ with $\Gamma$ being the set of all countries, or $G(p)=1-e^{-\Phi p^{\theta}}$. Therefore, $P=\exp \int_{0}^{\infty} \ln (p) d G(p)=e^{-\gamma / \theta} \Phi^{-1 / \theta}$, where $\gamma$ is Euler's constant (i.e., $\gamma \equiv-\int_{0}^{\infty} \ln (x) e^{-x} d x$ ). Readers familiar with Eaton and Kortum (2001) will note that this is slightly different from their result, namely $P=\gamma \Phi^{-1 / \theta}$. This difference is due to an inconsequential mistake in Eaton and Kortum (2001).

${ }^{15}$ This just requires showing that $T_{m} w_{m}^{-\theta}$ is higher than $T_{1} w_{1}^{-\theta}+T_{2} w_{2}^{-\theta}$ for the wages $w_{1}$ and $w_{2}$ that prevail with no offshoring. But, using $w_{i}=\delta\left(T_{i} / L_{i}\right)^{\kappa}$ for $i=1,2, m$, then this follows from the concavity of the function $f(x)=x^{\kappa \theta}$.

${ }^{16}$ Note that $w_{1}$ and $w_{2}$ are different under full offshoring than with no offshoring, but this is captured by the terms-of-trade effect. The productivity effect relies on $w_{2}$ being lower than $w_{1}$ in a particular equilibrium (see below).
} 
PROPOSITION 1: There is full offshoring if $\alpha \geq \bar{\alpha}$. Under full offshoring, $w_{1}$ and $w_{1} / P$ are lower, and $w_{2}$ and $w_{2} / P$ are higher than with no offshoring.

To understand why the TOT effect dominates the world-efficiency effect, note that the full offshoring equilibrium is equivalent to the equilibrium that results when $\Delta$ workers are reallocated from country 2 to country 1 , where $\Delta$ is given implicitly by $T_{1} /\left(L_{1}+\Delta\right)=T_{m} / L_{m}=T_{2} /\left(L_{2}-\Delta\right)$. This can be verified simply by noting that, in this case, we would have $w_{1}=w_{2}=w_{m}$, just as under full offshoring. This reallocation of workers from 2 to 1 can be seen as the combination of two steps. First, an increase in $L_{1}$ by $\Delta$, and second, a decrease in $L_{2}$ by $\Delta$. Standard Ricardian trade theory implies that both of these steps lead to a decline in the real wage in country 1 . Hence, $w_{1} / P$ will be lower under full offshoring than with no offshoring (see also Davis and Weinstein 2002).

This result is derived for the case of frictionless trade in final goods. One concern is that this may overemphasize the importance of the TOT loses arising from offshoring. For example, the presence of nontraded goods would imply that the productivity gains from offshoring generate a weaker TOT deterioration. To explore this, imagine that a share $\xi$ of final goods are nontradable. The price index would now differ across countries, and would be $P_{i}=\tilde{\gamma}\left(\left(T_{i} c_{i}^{-\theta}\right)^{\xi} \Phi^{1-\xi}\right)^{-1 / \theta}$ in country $i$, but all the other results remain unchanged. In particular, relative wages are independent of $\xi$ and full offshoring still holds for $\alpha \geq \bar{\alpha}$. Letting $\omega_{1}^{F O}(\xi)$ and $\omega_{1}^{N O}(\xi)$ be the real wage in country 1 as a function of $\xi$ under full offshoring and no offshoring (i.e., $\beta=0$ ), respectively, then it is easy to show that $\omega_{1}^{F O}(\xi) / \omega_{1}^{N O}(\xi)$ $=\left[\omega_{1}^{F O}(0) / \omega_{1}^{N O}(0)\right]^{1-\xi}$. This implies that if $\omega_{1}^{N O}(0)>\omega_{1}^{F O}(0)$, as shown in Proposition 1 , then also $\omega_{1}^{N O}(\xi)>\omega_{1}^{F O}(\xi)$ for any $\xi \in[0,1]$. This shows that the presence of nontradable goods does not change the result in Proposition 1. This is because the presence of nontradable goods weakens the TOT and world-efficiency effects by exactly the same proportion.

A related issue relates to the presence of transportation costs for final goods. To retain the possibility of full offshoring between countries 1 and 2, assume that there are no transportation costs between these two countries, but allow such costs for trade in final goods between them and the rest of the world. In particular, assume that there are uniform transportation costs between all country pairs except between countries 1 and 2, among which there is frictionless trade. The equilibrium wage in these two countries is no longer given by $w_{m}=\delta\left(T_{m} / L_{m}\right)^{\kappa}$, but it is increasing in $T_{m} / L_{m}$. Since $T_{m} / L_{m}<T_{1} / L_{1}$, this immediately establishes that $w_{m}$ is lower than country 1's relative wage under no offshoring, just as in Proposition 1. Turning to the real wage, note again that the move from no offshoring to full offshoring can be seen as the reallocation of $\Delta$ (as defined above) workers from country 2 to country 1 , and this necessarily makes country 1 worse off.

\section{The Effect of Offshoring on Relative Wages}

Above, it was already shown that the wage in country 2 increases with $\alpha$ (see (8) and (9)). I now explore how $\alpha$ affects $w_{1}$. Solving for $w_{1}$ from (10) yields

$$
w_{1}=(1+\alpha) \tilde{w}_{1}-\alpha w_{2},
$$


where $\tilde{w}_{1} \equiv \delta\left(T_{1} / \tilde{L}_{1}\right)^{\kappa}$ is the wage that would prevail in country 1 with no offshoring if its labor supply was $\tilde{L}_{1}$. In other words, this would be the equilibrium wage if offshoring only generated a TOT effect but no productivity effect. Note that both $\tilde{w}_{1}$ and $w_{2}$ are affected by $\alpha$. Differentiating with respect to $\alpha$ and simplifying yields

$$
w_{1}^{\prime}=(1+\alpha) \tilde{w}_{1}^{\prime}-\alpha w_{2}^{\prime}+\left(w_{1}-w_{2}\right) /(1+\alpha) .
$$

The first term on the RHS of (14) captures the TOT effect. It is negative because $\tilde{w}_{1}^{\prime}=-\kappa \tilde{w}_{1} /(1+\alpha)<0$. Intuitively, as $\alpha$ increases the "effective" supply $\tilde{L}_{1}$ increases and this leads to a decline in the wage through a worsening of country 1's TOT. The second term is negative because, as shown above, $w_{2}$ is increasing in $\alpha$. This is simply a demand effect: as offshoring increases, this pushes up country 2's wages, and this hurts country 1, which uses country 2's labor as an input. This second term could also be seen as part of a broader TOT effect that takes into account the price that country 1 must pay for imported services. Finally, the third term on the RHS of (14) is the productivity effect, which is positive as long as $w_{1}>w_{2}$. This effect captures the idea that by having access to cheaper labor in country 2, country 1 achieves a decline in its costs, and this leads to higher wages there.

To characterize the net marginal effect of offshoring on wages in country 1, i.e., $w_{1}^{\prime}(\alpha)$, it is useful to note the following two points. First, the productivity effect depends positively on the wage difference $w_{1}-w_{2}$, which in turn is increasing in the ratio of per capita technology levels in country 1 relative to country 2 , or $\eta \cdot 17$ Thus, $w_{1}^{\prime}(\alpha)$ is more likely to be positive if $\eta$ is large. In particular, from (14) we get

$$
w_{1}^{\prime}(0)=w_{2}(0)\left[(1-\kappa) \eta^{\kappa}-1\right] .
$$

Thus, $w_{1}^{\prime}(0) \gtrless 0$ according to whether $\eta \gtrless(1-\kappa)^{-1 / \kappa}$. Second, as $\alpha$ gets close to $\bar{\alpha}$ the wage difference $w_{1}-w_{2}$ goes to zero and the productivity effect vanishes, so $w_{1}^{\prime}(\alpha)$ is necessarily negative for $\alpha$ close enough to $\bar{\alpha}$. These two points combined suggest that for $\eta \leq(1-\kappa)^{-1 / \kappa}$, the curve $w_{1}(\alpha)$ is always decreasing, whereas for $\eta>(1-\kappa)^{-1 / \kappa}$, this curve is shaped like an inverted $U$. The next Proposition establishes this result.

PROPOSITION 2: Consider $\alpha$ in the interval $[0, \bar{\alpha}]$. Along this interval, the function $w_{1}(\alpha)$ is concave. If $\eta \leq(1-\kappa)^{-1 / \kappa}$, then $w_{1}(\alpha)$ is decreasing, whereas if $\eta>(1-\kappa)^{-1 / \kappa}$, then $w_{1}(\alpha)$ is shaped like an inverted $U$.

\section{E. The Effect of Offshoring on Real Wages}

To explore the effects of offshoring on real wages, we need to bring the worldefficiency effect into the analysis. As one would expect, offshoring decreases the price index $P$. Intuitively, an increase in $\alpha$ effectively implies more possibilities to

\footnotetext{
${ }^{17}$ The result that the gains from offshoring are more likely to be positive when the wage gap is higher is also present in Kohler (2004).
} 
trade, and this increases worldwide efficiency. The following proposition formalizes this result:

PROPOSITION 3: The price index $P$ is decreasing in $\alpha \in[0, \bar{\alpha}]$.

Since $w_{2}(\alpha)$ is increasing, then clearly $w_{2}(\alpha) / P(\alpha)$ will also be increasing. Similarly, if $w_{1}(\alpha)$ is increasing, then $w_{1}(\alpha) / P(\alpha)$ will be increasing as well. But what happens when $w_{1}(\alpha)$ is decreasing? The following Proposition shows that the characterization of $w_{1}(\alpha) / P(\alpha)$ is very similar to the characterization of $w_{1}(\alpha)$ in Proposition 2.

PROPOSITION 4: Consider $\alpha$ in the interval $[0, \bar{\alpha}]$. There exists $\hat{\eta}$, such that if $\eta \leq \hat{\eta}$, then $w_{1} / P$ is decreasing in $\alpha$, while if $\eta>\hat{\eta}$, then $w_{1} / P$ is shaped like an inverted $U$ as a function of $\alpha$.

This proposition shows that when fragmentation is sufficiently high, then further increases in fragmentation (and offshoring) necessarily hurt the rich country. This arises because the productivity and world-efficiency effects are dominated by the TOT and demand effects. A natural question here is whether an appropriate tariff or export tax could prevent such a negative impact. The working paper version of this paper explores this idea formally, focusing on the case of an export tax (the impact of a tariff would be equivalent). To derive analytical results, I consider the region composed of countries 1 and 2 as a "small economy," in the Fernando Alvarez and Robert E. Lucas (2005) sense of the limit of a sequence in which the ratios $k_{i}=T_{i} / L_{i}$ for $i=1,2$ and $L_{2} / L_{1}$ remain constant, but $L_{1} \rightarrow 0$. The results reveal that, under an appropriate export tax, an increase in fragmentation never makes the economy worse off. This is analogous to the well-known proposition that an optimal tariff or export tax rules out the possibility of immiserizing growth for a large economy (Bhagwati 1958).

\section{The Dynamic Model}

The previous section analyzed the effects of offshoring in a static model in which technology levels are fixed. This section explores how these results are affected when technology levels are endogenous in a fully dynamic model. The "short run" of this dynamic model will be equivalent to the static model analyzed above.

Technological progress is modeled as in Eaton and Kortum (2001). People choose to do research or work in the productive sector. Recall that in the previous section, we used $L_{i}$ to denote the number of workers engaged in production (including producing intermediate services as part of offshoring operations for other countries). Letting $L_{i t}^{F}$ be the total labor force and $R_{i t}$ be the number of people working as researchers in country $i$ at time $t$, then the full employment condition is $R_{i t}+L_{i t}=L_{i t}^{F}$. I assume that $L_{i t}^{F}$ grows at a constant rate $g_{L}$ that is common across countries. Also, I assume that the reallocation of workers between production and research is sluggish. This implies that $L_{i t}$ will be a state variable, and hence fixed in the short run (as in the previous section and Section IIA). To simplify, I assume that people are born as 
producers or researchers in proportion to the current population, and then at each point in time people get a chance to switch sectors at a constant and exogenous probability $v_{P}\left(v_{R}\right)$ for those in production (research). For future purposes, note that in steady state people will be happy to stay where they are born, so $v_{P}$ and $v_{R}$ will not be relevant for the steady state analysis in Section IIB. The size of $v_{P}$ and $v_{R}$ will affect the transition path after the economy is hit by a shock that changes the steady state allocation of people between research and production, as I consider in Section IIC.

A researcher in country $i$ draws technologies or "ideas" at a Poisson rate $\phi_{i}$. This parameter reflects research productivity and may vary across countries. Letting $T_{i t}$ be the total number of ideas that have been generated in country $i$ up to time $t$, then $\dot{T}_{i t}=\phi_{i} R_{i t}$ and

$$
T_{i t}=\phi_{i} \int_{0}^{t} R_{i s} d s .
$$

Each idea has two characteristics: the good $j \in[0,1]$ to which it applies, and its productivity $q$. Each of these characteristics is modeled as the realization of a random variable. $j$ is distributed uniformly over the interval $[0,1]$, while $q$ is distributed Pareto with parameter $\theta>1$. Formally, for $q \geq 1$, it is assumed that

$$
H(q)=\operatorname{Pr}\left[q^{\prime} \leq q\right]=1-q^{-\theta}
$$

Let $z_{i t}(j)$ be the maximum $q$ over ideas that apply to good $j$ in country $i$ at time $t$. It can be shown that the distribution of $z_{i t}(j)$ (which will be independent across goods and countries) has the Fréchet form, as in (2), with $T_{i t}$ given by (15) 18 In other words, the process for the arrival of ideas specified here leads to the Fréchet productivity frontier postulated in the static model, with the parameter $\theta$ in the Fréchet distribution coming from the parameter $\theta$ in the Pareto distribution of the quality of ideas, and the parameter $T_{i}$ growing over time and being equal to the stock of ideas in country $i$ at time $t$.

Researchers sell their ideas to firms that engage in Bertrand competition with other firms in the worldwide market for consumer goods. ${ }^{19}$ Consider the competition for a particular good. Only the firms holding the best idea for this good within some country have a chance of surviving the competition in the international market. Thus, the country that captures the worldwide market for good $j$ at time $t$ is given by $\arg \min _{i}\left\{c_{i} / z_{i t}(j)\right\}$.

The firm that captures the worldwide market for a good will make positive quasiprofits by charging a mark-up that depends on the second-least unit cost. Eaton and Kortum (2001) show that this mark-up is also distributed Pareto with parameter $\theta$,

\footnotetext{
${ }^{18}$ To derive this result, note that the number of ideas $k$ that have arrived for any good at time $t$ is distributed Poisson with parameter $T_{i t}$, so $\operatorname{Pr}\left(k^{\prime}=k\right)=e^{-T_{i t}} T_{i t}^{k} / k !$. Hence, $\operatorname{Pr}\left(z_{i t}^{\prime} \leq z\right)=\sum_{k=0}^{\infty}\left(e^{-T_{i t}} T_{i t}^{k} / k !\right) H(z)^{k}$, which given $\sum_{k=0}^{\infty} x^{k} / k !=e^{x}$ implies $\operatorname{Pr}\left(z_{i t}^{\prime} \leq z\right)=F_{i t}(z)=\exp \left[-T_{i t} z^{-\theta}\right]$ for $z \geq 1$. Note that since $H(q)$ is defined for $q \geq 1$, then this distribution is defined for $z \geq 1$, whereas the distribution in (2) is defined for $z \geq 0$. But, as discussed in footnote 9 of Eaton and Kortum (2001), this difference gets arbitrarily small as the $T$ s get large, so one can safely ignore this difference.

${ }^{19}$ As in Eaton and Kortum (2001), I assume that ideas can only be used in the country in which they originate. See footnote 26 .
} 
or $m \sim H(m) 20$ This is the distribution for the mark-up charged by firms from any country, and is constant through time. Letting $Y_{t}$ denote worldwide income at time $t$, then (given the assumed preferences) this is also the worldwide expenditure on every good. Hence, if a firm charges a mark-up $m$, then its profits are $Y_{t}(1-(1 / m))$, and total worldwide profits are

$$
Y_{t} \int_{1}^{\infty}(1-(1 / m)) d H(m)=\kappa Y_{t} .
$$

Since country $i$ captures the worldwide market for a share $\pi_{i t}=T_{i t} c_{i t}{ }^{-\theta} / \Phi_{t}$ of goods, its total income is $\pi_{i t} Y_{t}$, and its total profits are a share $\kappa$ of that.

Letting $d_{i t}$ be the probability of a random idea from country $i$ having a market at time $t$, then the expected profits of a random idea from country $i$ are $\kappa d_{i t} Y_{t}$. Thus, the expected discounted value of a random idea from country $i$ at time $t$ is given by

$$
V_{i t}=\kappa \int_{t}^{\infty} e^{-\rho(s-t)}\left(P_{t} / P_{s}\right) d_{i s} Y_{s} d s,
$$

where $\rho$ is the discount rate in consumers' intertemporal utility function, $u_{t}=\int_{0}^{\infty} e^{-\rho(s-t)} U_{s} d s$, and where $P_{t}$ is the price index in (13). 21

Eaton and $\operatorname{Kortum}(2001)$ show that $d_{i t}=\pi_{i t} / T_{i t}{ }^{22}$. To understand this result, recall that $\pi_{i t}$ is the share of worldwide spending devoted to purchases from country $i$ and also the probability that country $i$ is the least-cost producer for a particular good. For an idea in country $i$ to have a market it must be the best idea in country $i$, and it must beat the competition from all other countries. The probability that a random idea is the best idea in country $i$ is simply $1 / T_{i t}$, whereas the probability that the idea beats the foreign competition is $\pi_{i t}$.

\section{A. Short-Run Analysis}

At any point in time both $L_{i t}$ and $T_{i t}$ are fixed, just as in the static model. Thus, the only difference between the full dynamic model and the static model of the previous section regarding the short-run implications of offshoring is the market structure. In the static model there is perfect competition, whereas in the dynamic model technologies are owned by firms that engage in Bertrand competition. It turns out,

${ }^{20}$ To see this, recall from footnote 14 that the distribution of prices is $G_{t}(p)=e^{-\Phi_{t} p^{-\theta}}$. Thus, the probability that an entrepreneur with an idea of quality $q$ in country $i$ can charge a mark-up at least as high as $m$ is $1-G_{t}\left(m w_{i} / q\right)$. Hence, the probability that an idea of unknown quality from country $i$ can charge a mark-up of at least $m$ is $d_{i t}(m)=\int_{1}^{\infty}\left[1-G_{t}\left(m w_{i} / q\right)\right] d H(q) \approx\left(m w_{i}\right)^{-\theta} / \Phi_{t}$, where the approximation is arbitrarily accurate as the $T$ s get large (see Eaton and Kortum 2001, footnote 9). Conditional on selling at all, the distribution of the mark-up is then $\operatorname{Pr}[M \leq m \mid M \geq 1]=\left[d_{i t}(1)-d_{i t}(m)\right] / d_{i t}(1)=H(m)$. This is independent of source and time. Hence, this is also the distribution of the mark-up across all firms in the world.

${ }^{21}$ The linearity assumption for intertemporal preferences is made to simplify the analysis. The short-run and steady-state results are clearly independent of this assumption. As to the transition dynamics in subsection IIC, the same results would obtain under a more general specification of intertemporal preferences as long as countries 1 and 2 were able to access international capital markets. See footnote 30 .

${ }^{22}$ Formally, note from footnote 20 that the probability that an idea of unknown quality from country $i$ is competitive (i.e., $m \geq 1$ ) is simply $d_{i t}=d_{i t}(1)=w_{i t}{ }^{-\theta} / \Phi_{t}=\pi_{i t} / T_{i t}$. 
however, that the existence of mark-ups and profits under Bertrand competition has no effect on any of the comparative statics results derived under perfect competition. This is because, as explained above, the profit share is common across countries.

To see this formally, note that trade balance now requires that exports of goods and offshoring services plus domestic sales be equal to wages plus imports of offshoring services plus profits. Since the value of exports and domestic sales of goods is $\pi_{i t} Y_{t}$, and profits are a share $\kappa$ of this value, then we can equivalently state that trade balance requires $(1-\kappa) \pi_{i t} Y_{t}$ plus exports of offshoring services to equal wages paid to domestic and foreign workers (through offshoring). Thus, the trade balance conditions in the static model in equations (3), (6), and (7) are simply adjusted by multiplying $Y_{t}$ by $1-\kappa$. All the results for wages in (4), (8), and (10) are not affected, and the comparative statics results of the previous section remain valid.

\section{B. Steady State Analysis}

In steady state, $r_{i t} \equiv R_{i t} / L_{i t}^{F}$ will be constant, so the growth rate of the stock of ideas $T_{i t}$ will be $\dot{T}_{i t} / T_{i t}=g_{L}$, and its level will be

$$
T_{i t}=\left(\phi_{i} r_{i} / g_{L}\right) L_{i t}^{F}
$$

The choice of country $N$ 's labor as the numeraire implies that steady-state wages will be constant, $w_{i t}=w_{i}$, so, from (13), we can see that $P_{t}$ falls at a rate equal to $\theta g_{L}$, so $P_{s}=P_{t} e^{-\left(g_{L} / \theta\right)(s-t)}$. In steady state, $\pi_{i t}$ is also constant. Moreover, equality between sales and expenditures, or trade balance, entails $\pi_{i} Y_{s}=Y_{i s}$. These results imply that

$$
V_{i t}=\kappa \int_{t}^{\infty} e^{-\left(\rho-g_{L} / \theta\right)(s-t)}\left(Y_{i s} / T_{i s}\right) d s .
$$

Consider country 1 . Total expenditures are equal to wages paid, the cost of offshoring, and profits,

$$
Y_{1 t}=w_{1} L_{1 t}+w_{2} \alpha L_{1 t}+\kappa Y_{1 t}
$$

Using $L_{1 t}=\left(1-r_{1}\right) L_{1 t}^{F}$, and solving for $Y_{1 t}$ in (18), plugging the resulting expression for $Y_{1 t}$ into (17), using (16), and assuming $\theta \rho>g_{L}$ yields

$$
V_{1}=w_{1}\left[1-r_{1}+\alpha\left(1-r_{1}\right) \frac{w_{2}}{w_{1}}\right]\left(\frac{g_{L}}{\phi_{1} r_{1}}\right) \frac{1}{\theta \rho-g_{L}} .
$$

Turning to country 2 , we have

$$
Y_{2 t}=w_{2} L_{2 t}-w_{2} \alpha\left(1-r_{1}\right) \varphi L_{2 t}^{F}+\kappa Y_{2 t}
$$


where $\varphi \equiv L_{1 t}^{F} / L_{2 t}^{F}$. A similar procedure yields

$$
V_{2}=w_{2}\left[1-r_{2}-\alpha\left(1-r_{1}\right) \varphi\right]\left(\frac{g_{L}}{\phi_{2} r_{2}}\right) \frac{1}{\theta \rho-g_{L}} .
$$

For all the rest of countries $(i \neq 1,2)$, the corresponding expected value of an idea can be derived from the previous results by simply plugging in $\alpha=0$, hence

$$
V_{i}=w_{i}\left(1-r_{i}\right)\left(\frac{g_{L}}{\phi_{i} r_{i}}\right) \frac{1}{\theta \rho-g_{L}} .
$$

In equilibrium, the expected payoff to research must be equal to the wage in every country. This entails $\phi_{i} V_{i}=w_{i}$. For countries $i \neq 1,2$ this can be solved to yield

$$
r_{i}=r \equiv g_{L} / \theta \rho .
$$

This implies that differences in $\phi_{i}$ do not affect the proportion of workers engaged in research. ${ }^{23}$ For countries 1 and 2 the equilibrium conditions are (after some simplification)

$$
r_{1} / r=1+\alpha\left(1-r_{1}\right) w_{2} / w_{1}
$$

and

$$
r_{2} / r=1-\alpha\left(1-r_{1}\right) \varphi
$$

Given the wage ratio $w_{2} / w_{1}$, these two equations determine the research intensities in countries 1 and 2.

Using (16) and $L_{i t}=\left(1-r_{i}\right) L_{i t}^{F}$ yields

$$
\frac{T_{i s}}{L_{i s}}=\frac{\phi_{i} r_{i}}{g_{L}\left(1-r_{i}\right)} .
$$

Thus, from (4) and (23), we see that for $i \neq 1,2$ the steady-state equilibrium wage is

$$
w_{i}=\left(\phi_{i} / \phi_{N}\right)^{\kappa} \text {. }
$$

This is the same as in Eaton and Kortum (2001) and implies that wages differ only because of differences in research productivity $\phi_{i}$. Notice that with no offshoring (i.e., $\alpha=0$ ) wages in countries 1 and 2 are also given by (27). Thus, the condition that $w_{1}>w_{2}$ in steady state with no offshoring is that $\phi_{1}>\phi_{2}$, which I assume

\footnotetext{
${ }^{23}$ Also note that $r$ does not depend on country size or openness. This is because although larger markets lead to higher profits for successful innovators, stronger competition reduces the probability of being successful, and in this model these two effects exactly offset each other (see Eaton and Kortum 2001).
} 
henceforth. (This is the long-run counterpart to the condition $\eta>1$ in the previous section.)

I now turn to the determination of steady-state wages in countries 1 and 2, when $\alpha>0$. As long as the resource constraint $\alpha\left(1-r_{1}\right) L_{1 t}^{F} \leq L_{2 t}^{F}$ is satisfied, steadystage wages in countries 1 and 2 are determined by equations (8), (9), (10), and (11) together with $L_{i t}=\left(1-r_{i}\right) L_{i t}^{F}$ and equations (24) and (25). ${ }^{24}$ Consider first the determination of $w_{2}$. From (8), we can get

$$
w_{2}=\left(\frac{\phi_{2} r_{2}}{\phi_{N} r /(1-r)} \frac{1}{1-r_{2}-\alpha\left(1-r_{1}\right) \varphi}\right)^{\kappa} \text {. }
$$

Using (25), then

$$
w_{2}=\left(\phi_{2} / \phi_{N}\right)^{\kappa}
$$

which is the same as in the case of no offshoring. The reason for this result is that the decline in $\tilde{L}_{2}$ generated by increased offshoring in the static model is now exactly compensated by a decline in $T_{2}$ caused by a decline in $r_{2}$ (see below).

Turning to $w_{1}$, recall from (10) that $\left((1-\beta) w_{1}+\beta w_{2}\right)=\left(T_{N s} / L_{N s}\right)^{-\kappa}\left(T_{1 s} / \tilde{L}_{1 s}\right)^{\kappa}$. With endogenous research the ratio $T_{1 s} / \tilde{L}_{1 s}$ now depends on research efforts as well as the extent of offshoring. In fact, from (24), (26), and (11) we get

$$
T_{1 s} / \tilde{L}_{1 s}=\left(\frac{T_{N s} / L_{N s}}{\phi_{N}}\right)\left(\frac{\phi_{1}}{w_{1}}\right)\left((1-\beta) w_{1}+\beta w_{2}\right) .
$$

The equilibrium steady-state wage in country 1 is then determined by

$$
(1-\beta) w_{1}+\beta w_{2}=\left(\frac{\phi_{1} / \phi_{N}}{w_{1}}\right)^{\kappa}\left((1-\beta) w_{1}+\beta w_{2}\right)^{\kappa} .
$$

The $L H S$ is the unit cost of the common input, whereas the RHS is proportional to $\left(T_{1 s} / \tilde{L}_{1 s}\right)^{\kappa}$ and captures the impact of offshoring and research on country 1's TOT. It is easy to show that, given our assumption that $\phi_{1}>\phi_{2}$, the level of $w_{1}$ determined by equation (29) is higher than $w_{2} \cdot{ }^{25,26}$ But this implies that offshoring lowers the unit cost of the common input (i.e., $L H S$ is increasing in $\beta$ ). This represents the productivity effect discussed above. Turning to the $R H S$, note that an increase in $\beta$ decreases this term, a reflection of the negative TOT effect discussed above. Which

\footnotetext{
${ }^{24}$ For this steady-state analysis, it is no longer necessary to worry about the possibility of factor price equalization and the outsourcing constraint becoming nonbinding. The reason is that, as will be shown below, $w_{2}(\alpha)$ is constant, whereas $w_{1}(\alpha)$ is increasing. Thus, since $w_{1}(0)>w_{2}(0)$ by assumption, then $w_{2}(\alpha)>w_{1}(\alpha)$ for all $\alpha>0$.

${ }^{25}$ To see this, note that this is equivalent to saying that the LHS of (29) is lower than the RHS of this same equation if $w_{1}$ were equal to $w_{2}$, or $w_{2}^{1-\kappa}<\left(\phi_{1} / w_{2} \phi_{N}\right)^{\kappa}$, but this is equivalent to $\phi_{2}<\phi_{1}$.

${ }^{26}$ As I mentioned in footnote 19 , I assume that there is no international trade in ideas. It is easy to see from (27) and $\kappa<1$ that if $\phi_{j}>\phi_{i}$ then $V_{j}<V_{i}$, which implies that innovators in $j$ would want to sell their ideas to $i$. Since $w_{1}$ and therefore $V_{1}$ is increasing in $\beta$, this implies that if $\beta$ is low, then $V_{1}<V_{2}$, so innovators in 1 would want to export ideas to 2 , whereas, for high enough $\beta$, we would have $V_{1}>V_{2}$, so innovators in 2 would want to export ideas to 1. Exploring the full implications of this kind of trade is left for future research.
} 
effect dominates? Since $\kappa<1$, then the productivity effect always dominates, so $w_{1}$ is increasing in $\beta 27,28$

So far, I have ignored the resource constraint in country 2 that the amount of labor used for exporting services to country 1 must be lower than its total labor force, namely $\alpha\left(1-r_{1}\right) L_{1 t}^{F} \leq L_{2 t}^{F}$. In fact, it can be shown from the results above that if $r>\phi_{1} /\left(\left(\phi_{1}+\phi_{2}\right) / \varphi\right)$, then the resource constraint is satisfied for all $\alpha$. Otherwise, there exists a level of $\alpha, \hat{\alpha}$, such that the resource constraint is binding for $\alpha>\hat{\alpha}$. In this case the equilibrium entails wage equalization, with all workers in country 2 employed in offshoring operations for country 1.

Again, the previous results relate to wages in countries 1 and 2 relative to some third country $N$. But it can be shown that the price index $P$ will decline with offshoring, as the efficiency gains in the static model are only expanded in this dynamic model as offshoring allows a reallocation of labor toward the activity in which they have comparative advantage (research in country 1 and production in country 2). The following proposition summarizes these results.

PROPOSITION 5: As long as the resource constraint in country 2 is nonbinding, an increase in $\alpha$ increases the wage in country 1 , whereas the wage in country 2 is not affected. The real wages $w_{i} / P$ increase in all countries.

What happens to $r_{1}$ and $r_{2}$ as $\alpha$ increases? Equation (24) implies

$$
r_{1} L_{1 t}^{F}=r\left[L_{1 t}^{F}+\alpha\left(1-r_{1}\right) L_{1 t}^{F} w_{2} / w_{1}\right] .
$$

The term $\alpha\left(1-r_{1}\right) L_{1 t}^{F} w_{2} / w_{1}$ is the number of workers indirectly hired by country 1 from country 2 through offshoring, adjusting for the wage ratio. Thus, this equation says that the number of people doing research in country 1 is a proportion $r$ of the total labor force in country 1 including the workers indirectly working in country 1 through offshoring (adjusting for wages). Thus, $r_{1}$ is necessarily higher with offshoring than without offshoring. Moreover, it can be shown that $\alpha\left(1-r_{1}\right) w_{2} / w_{1}$ is increasing in $\alpha$, so it is also the case that as offshoring increases the research intensity $r_{1}$ in country 1 increases.

Turning to country 2 , rearranging equation (25), we get

$$
r_{2} L_{2 t}^{F}=r\left(L_{2 t}^{F}-\alpha\left(1-r_{1}\right) L_{1 t}^{F}\right) .
$$

Analogously to the result for country 1, this expression says that the number of people doing research in country 2 is a proportion $r$ of its total labor force, excluding the workers producing services for export through offshoring operations. This implies that $r_{2}<$ $r$ as long as $\alpha>0$. More generally, it can be shown that $r_{2}$ is decreasing in $\alpha$. Formally,

\footnotetext{
${ }^{27}$ Formally, from $(29)$, we get $\left[(1-\beta) w_{1}+\beta w_{2}\right]^{1-\kappa}=\left(\left[\phi_{1} / \phi_{N}\right] / w_{1}\right)^{\kappa}$. The LHS is increasing in $w_{1}$ while the RHS is decreasing, and, since $w_{1}>w_{2}$, then an increase in $\beta$ implies a decline in the LHS, and an increase in the equilibrium $w_{1}$.

${ }^{28}$ A natural question is whether country 1 would also want to offshore research to country 2 . This would require $w_{1} / \phi_{1}>w_{2} / \phi_{2}$. But it can be shown, (28) and (29), that this is never satisfied for any $\beta \in[0,1]$.
} 
PROPOSITION 6: The research intensity $r_{1}$ in country 1 increases while the research intensity $r_{2}$ in country 2 decreases as $\alpha$ increases.

\section{Transition Dynamics}

Imagine an unexpected increase in fragmentation at time $t_{0}$. We know from the previous section that if the increase in $\alpha$ is large enough, it would lead to a decline in the real wage in country 1 at time $t_{0}$. As time goes by, however, workers in country 1 would switch from production to research, increasing $T_{1 t} / L_{1 t}$ and improving country 1's TOT. In the new steady state, the real wage in country 1 would be higher than it was before the increase in $\alpha$. There are then two opposite effects of a large (and unexpected) increase in fragmentation: a negative short-run effect and a positive long-run effect. What is the net effect for utility at time $t=0$ ?

To answer this question, I analyze the transition dynamics after a positive and unexpected shock to $\alpha$. I restrict the analysis to the limiting case in which the region composed of countries 1 and 2 is vanishingly small. This assumption implies that the rest of the world (i.e., countries $i \neq 1,2$ ) is not affected by anything that happens in countries 1 and 2, and that $P_{t}$ continues to fall at rate $g_{L} / \theta$ even after a shock to $\alpha$. The working paper version of this paper contains the formal analysis. Here, I just describe the results informally.

Recall that wages $w_{1 t}$ and $w_{2 t}$ are determined by the ratios $T_{1 t} / \tilde{L}_{1 t}$ and $T_{2 t} / \tilde{L}_{2 t}($ see equations (8)-(11)), where $\tilde{L}_{1 t}=(1+\alpha)\left(1-r_{1 t}\right) L_{1 t}^{F}$ and $\tilde{L}_{2 t}=\left(1-r_{2 t} L_{2 t}^{F}-\right.$ $\alpha\left(1-\mathrm{r}_{1 t}\right) L_{1 t}^{F}$. One can think of these ratios as a function of $\alpha$ together with the ratios $x_{1 t} \equiv T_{1 t} / L_{1 t}^{F}$ and $x_{2 t} \equiv T_{2 t} / L_{2 t}^{F}$, and the research shares $r_{1 t}$ and $r_{2 t}$. The positive shock to $\alpha$ throws the system out of steady state, with a low initial value of $x_{1 t}$ and a high initial value of $x_{2 t}$ (relative to their new steady state levels). Assuming that the exit rates $v_{P}$ and $v_{R}$ are sufficiently large and that $v_{R}$ is large relative to $v_{P}$, the equilibrium adjustment after an unexpected increase in $\alpha$ has three stages. In the first stage $\phi_{1} V_{1 t}>\mathrm{w}_{1 t}$ and $\phi_{2} V_{2 t}<w_{2 t}$, so there is maximal entry into research in country 1 and maximal exit from research in country 2 . This stage ends when $w_{2 t}$ reaches its steady state, $w_{2}{ }^{2}{ }^{29}$ In the second stage, $\phi_{1} V_{1 t}>w_{1 t}$ and $\phi_{2} V_{2 t}=w_{2 t}=w_{2}$, so maximal entry into research continues in country 1 while the constraint on exit from research in country 2 is no longer binding. This stage ends when $\mathrm{w}_{1 t}$ reaches its steady state, $w_{1}$. The third stage entails $\phi_{i} V_{i t}=w_{i t}=w_{i}$ for $i=1,2$, so that wages in countries 1 and 2 are at their steady state values, and $r_{1 t}$ and $r_{2 t}$ adjust in response to the continued movement of $x_{1 t}$ and $x_{2 t}$ toward their steady-state values. Under these conditions, it is clear that if $v_{P}$ and $v_{R}$ are very high, then the first two stages of the adjustment process will be very short, and the adjustment will entail wages being at their new steady-state values most of the time. Since an increase in $\alpha$ brings about an increase in the steady-state wage of country 1 , then this country must benefit from such a shock even if it experiences some losses in the short run. Country 2 also experiences a positive welfare effect, because wages are momentarily higher

\footnotetext{
${ }^{29}$ This necessarily happens before $w_{1 t}$ reaches its steady state thanks to the assumption that $v_{R}$ is large relative to $v_{P}$.
} 
there after the shock, although they rapidly converge to the same level as before the shock 30

This analysis has focused on the effects of an unexpected shock in fragmentation. If the shock is anticipated, then the previous analysis suggests that the effects should be even more positive for country 1 , as it can start reallocating its labor from production to research even before the shock and, in that way, lessen the TOT deterioration. The opposite occurs for country 2 , where the temporary increase in its TOT may vanish if the shock is anticipated. Although there are no clear statistics that one could use to measure fragmentation, it is reasonable to assume that it is a gradual and somewhat anticipated process rather than a sudden shock. In this case, the analysis suggests that as long as reallocation between production and research is not too sluggish, the net effect should be positive for rich countries and small (but positive) for poor countries.

\section{Offshoring and Immigration}

This kind of analysis can also be used to shed light on the effects of migration, which in turn may allow us to gain some intuition about the effects of offshoring just described. ${ }^{31}$ Consider again countries 1 and 2 , with $w_{1}>w_{2}$ thanks to $\eta>1$ and no offshoring, and imagine that a restricted share $\iota$ of people from country 2 can costlessly migrate to country 1 . As $\iota$ increases, there is a short-run (with constant $T$ 's) decline in $\eta$, which leads to a decline in $w_{1}$ and an increase in $w_{2}$. This captures the idea put forth by Davis and Weinstein (2002) that immigration leads to losses to the host country due to a deterioration of its TOT.

But, again, this is only in the short run. In the Eaton and Kortum (2001) model with endogenous technology levels, immigration leads to an expansion of research in country 1 and a contraction of research in country 2 in such a way that (in steady state) $T_{1} / L_{1}$ and $T_{2} / L_{2}$ remain constant because $T_{i} / L_{i}=\phi_{i} r /(1-r) g_{L}$ doesn't depend on $L_{i}^{F}$. Wages $w_{1}$ and $w_{2}$ are not affected, and the only effect is a decline in prices thanks to the increased efficiency generated by migration toward countries with higher research productivities (i.e., the long-run world efficiency effect). Thus, in the long run all countries gain equally, and the main beneficiaries of migration are the migrants themselves, who experience an increase in wages from $w_{2}$ to $w_{1} 32$

Let's compare these results of migration with those of offshoring in the long run. As shown in Section IIC, in steady state offshoring does not affect wages in country 2 , but wages in country 1 experience an increase. Thus, focusing on the long-run implications, offshoring is better for country 1 than immigration. The reason for this is that with migration, the receiving country ends up paying the high country 1

\footnotetext{
${ }^{30}$ These results are valid under the assumption that intertemporal preferences are linear. When the intertemporal elasticity of substitution is low and there are no international capital flows, my conjecture is that even with perfect mobility of people between research and the production sector, a large unexepected increase in fragmentation would decrease utility, as people would not be willing to decrease their consumption to allow for a large increase in research efforts to accelerate the transition.

${ }^{31}$ Baldwin and Robert-Nicaud (2007) relate the effects of offshoring to what they call "shadow migration."

${ }^{32}$ The result that the effect of immigration on wages is more beneficial in the long run than in the short run can also be obtained in the Hecksher-Ohlin model, as well as in models that allow for capital accumulation (see Paul Klein and Gustavo J. Ventura 2007, and Gianmarco I. P. Ottaviano and Giovanni Peri 2006).
} 
wage to immigrants, whereas with offshoring, country 1 firms pay the low country 2 wage to workers who remain in country 2 . Thus, whereas with migration, the main beneficiaries are the migrants, with offshoring, the main beneficiaries are workers in country 1, whose wage can now increase because of the efficiency gains from offshoring. .33

\section{An Extension}

I have assumed thus far that increasing offshoring is made possible by the raising capability to fragment the production process, and thereby arrange to have more intermediate services performed abroad. Alternatively, as in Kohler (2004) and Grossman and Rossi-Hansberg (2006), the expansion of offshoring could be seen as the consequence of a decline in the cost of importing these services. In fact, the model presented above could be interpreted in this light by assuming that a share $\beta$ of services can be offshored at no cost, whereas the rest entail an infinite cost of offshoring. A question is whether the results derived under this set-up generalize to other ways of modeling such costs. In this section, I present an extension of the model to explore this question, and then I extend the analysis to offshoring among three countries.

I assume that importing labor service $k$ entails an iceberg cost $\zeta(k) \geq 1$. The cost of labor service $k$ offshored to country 2 is then $\zeta(k) w_{2}$. Country 1 will procure service $k$ from country 2 if $\zeta(k) w_{2}<w_{1}$ and may do so if $\zeta(k) w_{2}=w_{1}$. Following the stochastic approach of Eaton and Kortum (2002), I assume that $\zeta(k)$ (for $k \in[0,1]$ ) is independently drawn from an exponential distribution with parameter $\lambda$ and a mass point at 1 . Formally, for any $k$ and $\hat{\zeta} \geq 1$ we have $\operatorname{Pr}(\zeta \leq \hat{\zeta})$ $=F(\hat{\zeta}, \lambda) \equiv 1-\exp (-\lambda \hat{\zeta})$, where $\lambda>0$. Note that a higher $\lambda$ implies lower average offshoring costs, and that as $\lambda \rightarrow 0$, then offshoring necessarily goes to zero. This stochastic approach will be particularly useful when I extend the analysis to more than two countries.

The goal is to understand the short-run and long-run effects of an increase in $\lambda$. Consider first the short run. Analogously to the results of Section I, when $\lambda$ is sufficiently high there is full offshoring, with wages in both country 1 and 2 equal to $w_{m}=\delta\left(T_{m} / L_{m}\right)^{\kappa}$ (recall that $T_{m}=T_{1}+T_{2}$ and $\left.L_{m}=L_{1}+L_{2}\right)$. The critical value for $\lambda, \lambda_{m}$, is implicitly defined by $F\left(1, \lambda_{m}\right)=\bar{\beta}$, where $\bar{\beta}=\bar{\alpha} /(1+\bar{\alpha})(\bar{\alpha}$ was defined in Section I). In other words, $\lambda$ needs to be high enough that the share of services for which there are no transportation costs $(\zeta(k)=1)$ is at least as high as the share of services that must be offshored for there to be full offshoring $(\bar{\beta})$. It is clear that the wage under full offshoring is higher than the wage that would prevail under no offshoring in country 2 , but lower than the corresponding wage in country 1 . Formally, letting $w_{i}(0)=\lim _{\lambda \rightarrow 0} w_{i}(\lambda)$, we have $w_{1}(0)>w_{m}>w_{2}(0)$. This result clearly also extends to real wages, so we can continue to say that the rich (poor) country is worse (better) off under full offshoring than with no fragmentation.

If $\lambda<\lambda_{m}$, the equilibrium entails $w_{1}>w_{2}$. I now characterize this equilibrium. Let $C_{1}(k) \equiv \min \left\{w_{1}, \zeta(k) w_{2}\right\}$ represent the cost of service $k$ for

\footnotetext{
${ }^{33}$ The point that offshoring leads to larger gains than migration because of the difference in the wage paid to the extra labor made available is discussed in Jones (2005).
} 
country 1. (Since all services are homogenous, from now on I supress the index $k$.) The cost $C_{1}$ can never be lower than $w_{2}$ and is lower than some $\hat{C}_{1}$ for $\hat{C}_{1} \in\left[w_{2}, w_{1}\left[\right.\right.$ if $\zeta w_{2}<\hat{C}_{1}$. This implies that for $\hat{C}_{1} \in\left[w_{2}, w_{1}\left[, \operatorname{Pr}\left(C_{1} \leq \hat{C}_{1}\right)\right.\right.$ $=\operatorname{Pr}\left(\zeta w_{2} \leq \hat{C}_{1}\right)=F\left(\hat{C}_{1} / w_{2}, \lambda\right)=F\left(\hat{C}_{1}, \lambda / w_{2}\right)$, so the distribution of the variable $C_{1}$ is given by

$$
\operatorname{Pr}\left(C_{1} \leq \hat{C}_{1}\right)= \begin{cases}0 & \text { if } \hat{C}_{1}<w_{2}, \\ F\left(\hat{C}_{1}, \lambda / w_{2}\right) & \text { if } \hat{C}_{1} \in\left[w_{2}, w_{1}[.\right. \\ 1 & \text { if } \hat{C}_{1} \geq w_{1}\end{cases}
$$

The unit cost of the common input in country 1 is simply the expectation of $C_{1}$ for this distribution. I will use $c_{1}(\mathbf{w})$ to denote this unit cost as a function of wages $\mathbf{w}$ $\equiv\left(w_{1}, w_{2}\right)$. This is given by

$$
c_{1}(\mathbf{w})=w_{2} F(1, \lambda)+\int_{w_{2}}^{w_{1}} x d F\left(x, \lambda / w_{2}\right)+w_{1}\left(1-F\left(w_{1}, \lambda / w_{2}\right)\right) .
$$

On the other hand, the unit cost of the common input in country 2 is simply $w_{2}$. Also, note that if $w_{1}>w_{2}$, then the share of services offshored to country 2 is $s(\mathbf{w})$ $=F\left(w_{1}, \lambda / w_{2}\right)$. Thus, following the same analysis as in Section I, the equilibrium conditions for $\lambda<\lambda_{m}$ are $c_{1}(\mathbf{w})=\delta\left(T_{1} / \tilde{L}_{1}\right)^{\kappa}$ and $w_{2}=\delta\left(T_{2} / \tilde{L}_{2}\right)^{\kappa}$ (as in equations (10) and (8)), but with

$$
\tilde{L}_{1}=L_{1} /(1-s(\mathbf{w}))
$$

and

$$
\tilde{L}_{2}=L_{2}-\Gamma(\mathbf{w}) s(\mathbf{w}) L_{1} /(1-s(\mathbf{w})),
$$

where $\Gamma(\mathbf{w})$ is the average transportation cost $\zeta$ associated with the offshored services and is given by

$$
\Gamma(\mathbf{w}) \equiv \frac{F(1, \lambda)+\left(1 / w_{2}\right) \int_{w_{2}}^{w_{1}} x d F\left(x, \lambda / w_{2}\right)}{s(\mathbf{w})} .
$$

Note that in these definitions of $\tilde{L}_{1}$ and $\tilde{L}_{2}$, the term $s(\mathbf{w})$ substitutes for $\beta$ in equations (11) and (9).

As shown in the Web Appendix, the sign of the partial derivative of $w_{1}$, with respect to $\lambda$, converges to $\left(w_{1} / w_{2}\right)^{2}(1-2 \kappa)-1$ as $\lambda \rightarrow 0$. This implies that, since $\kappa<1 / 2$ (because $\theta>1$ ), the curve $w_{1}(\lambda)$ will be upward sloping for low $\lambda$ if $w_{1}(0) / w_{2}(0)=\eta^{\kappa}$ is sufficiently high. This is similar to the result for $w_{1}(\alpha)$ in Proposition 2. I cannot analytically characterize the behavior of $w_{1}(\lambda)$ in the whole interval $\left[0, \lambda_{m}\right]$, but the finding that it behaves like $w_{1}(\alpha)$ at both extremes suggests that it too behaves like an inverted $U$ when $\eta$ is high enough, whereas it is everywhere 
decreasing if $\eta$ is low. All numerical simulations that I have performed are consistent with this conjecture.

Turning to the long-run equilibrium, the result that $w_{2}$ is fixed at $\left(\phi_{2} / \phi_{N}\right)^{\kappa}$ remains valid: offshoring costs only affect the quantity of labor used in country 2 to export services to country 1 , but the steady-state wage in country 2 is unaffected by this. As for country 1 , the wage is determined as in (29), but with $c_{1}(\mathbf{w})$ instead of $(1-\beta) w_{1}$ $+\beta w_{2}$, hence

$$
c_{1}(\mathbf{w})^{1-\kappa}=\left(\frac{\phi_{1} / \phi_{N}}{w_{1}}\right)^{\kappa}
$$

Simple derivation (see the Web Appendix) reveals that the curve $c_{1}(\mathbf{w})$ decreases with $\lambda$, hence, the steady state $w_{1}$ is increasing with $\lambda$. This implies that, similar to the results in Section II, in the long run, the rich country gains from a decline in the cost of offshoring, whereas the poor country gains, but only from the world efficiency effect.

Finally, I extend the model to allow for offshoring among countries 1, 2, and 3, where country 1 is the rich country, and country 2 is the poor country. Formally, I assume that $T_{1} / L_{1}>T_{3} / L_{3}>T_{2} / L_{2}$ and $\phi_{1}>\phi_{3}>\phi_{2}$. The (iceberg) costs of offshoring service $k$ to country $i=1,2,3$ are $\zeta_{i}(k)$, which are independently drawn from the same distribution, assumed to be exponential with a mass point at 1 and parameter $\lambda$. The Web Appendix contains the full characterization of equilibrium in the short run and the long run for this case. Here, I present a short discussion and the results of a numerical simulation.

Just as in the two country case, there is full offshoring among the three countries if $\lambda$ is higher than some critical level. Under full offshoring, $w_{1}(0)>w_{m}>w_{2}(0) .34$ The middle-income country is better off under full offshoring than with no offshoring if $T_{m} / L_{m}>T_{3} / L_{3}$.

To gain some additional understanding about the behavior of wages in relation to $\lambda$, I simulated the short-run equilibrium for $\theta=8$ (the central value of $\theta$ in Eaton and Kortum 2002) with $L_{1}=L_{2}=L_{3}$ and $T_{1}=1, T_{2}=0.04$, and $T=0.2$. Figure 1 shows the resulting wages as $\lambda$ goes from 0 to the value of $\lambda$ under which there is full offshoring. As in Section $\mathrm{I}, w_{2}$ is always increasing while $w_{1}$ behaves like an inverted U. (This last result no longer holds when $T_{1} / L_{1}$ is close to $T_{2} / L_{2}$, in which case $w_{1}$ is decreasing in $\lambda$.)

Turning to the long-run analysis, it is easy to show that the steady-state wage in country 2 is constant, whereas the steady-state wage in country 3 is increasing in $\lambda$. The reasoning for this result regarding country 3 exactly the same as for the result that the steady-state wage in country 1 is increasing in $\lambda$ in the two-country case. As to the wage in country 1 , there are two opposite effects from the increase in $\lambda$. On the one hand, this increases $w_{3}$, which has a negative effect on country 1 , but on the other hand, there is a direct and positive effect on $w_{1}$. In the numerical simulation for

\footnotetext{
${ }^{34}$ As above, we have $w_{m}=\delta\left(T_{m} / L_{m}\right)^{\kappa}$, but now $T_{m}=T_{1}+T_{2}+T_{3}$ and $L_{m}=L_{1}+L_{2}+L_{3}$.
} 


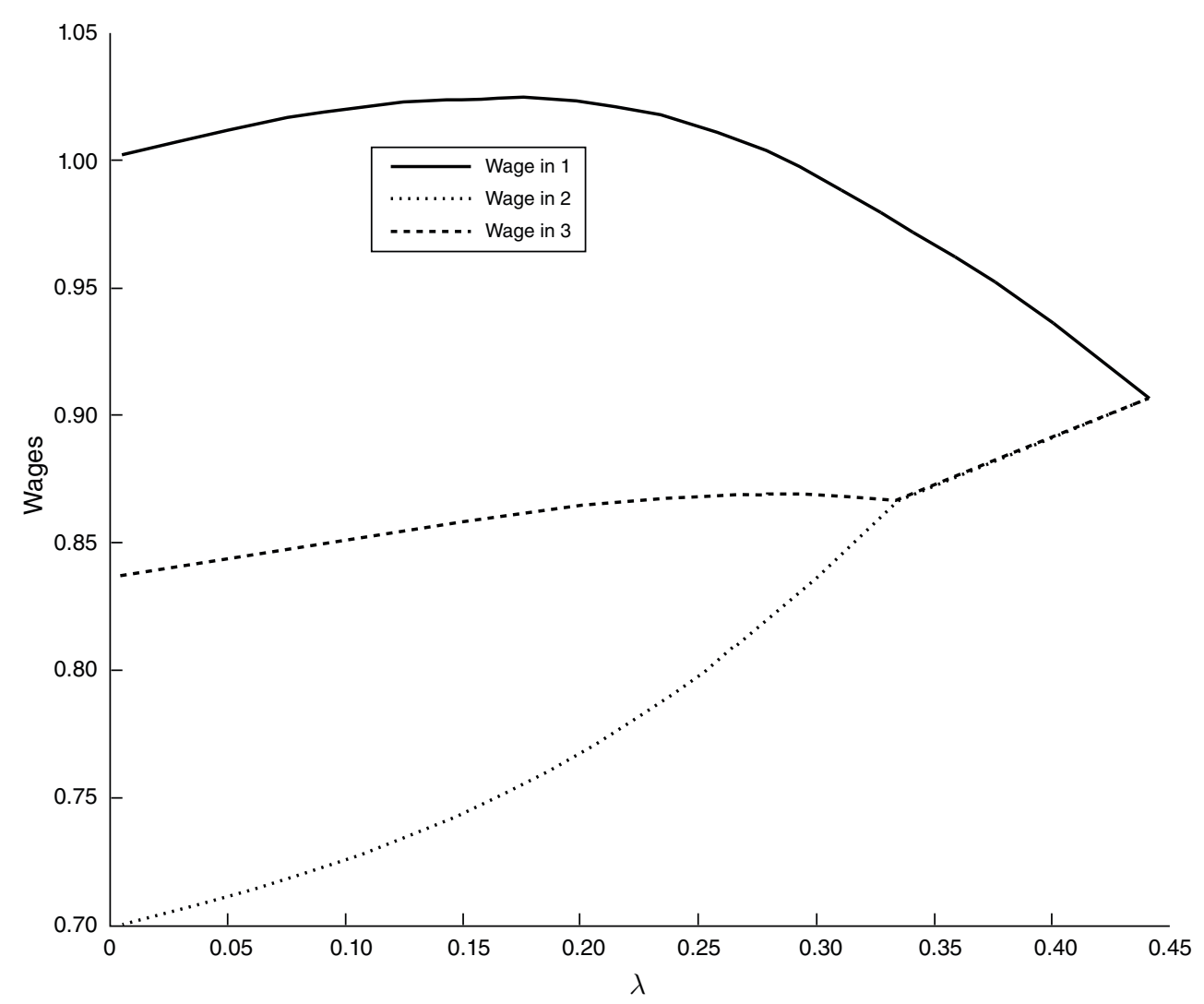

Figure 1. Wages Against $\lambda$ (Short run)

Note: This simulation uses $\delta=1, \theta=8, L_{1}=L_{2}=L_{3}=1$ and $T_{1}=1, T_{2}=0.04$, and $T_{3}=0.2$.

$\phi_{1} / \phi_{N}=1, \phi_{2} / \phi_{N}=0.04$, and $\phi_{3} / \phi_{N}=0.2$, illustrated in Figure $2, w_{1}$ is increasing in $\lambda$. This result also holds in all numerical simulations that I have performed.

\section{Conclusion}

Over the last few years, there has been much discussion about the possible effects of increased offshoring on rich countries. Those with a favorable view have focused on the productivity gains associated with increasing trade in services, while the critics have emphasized the negative implications for rich-country wages of what some have called "the death of distance" (Frances Cairncross 1997). In this paper, I have presented a model that captures both of these effects. A main result is that a large and unexpected increase in fragmentation necessarily harms the rich country and benefits the poor country in the short run. But this also triggers a reallocation of resources toward research in the rich country and toward production in the poor country. Such reallocations weaken the TOT effects of offshoring and imply that the long-run effect of increased fragmentation is always positive for the rich country. In contrast, the poor country derives no direct gains from offshoring and benefits only 


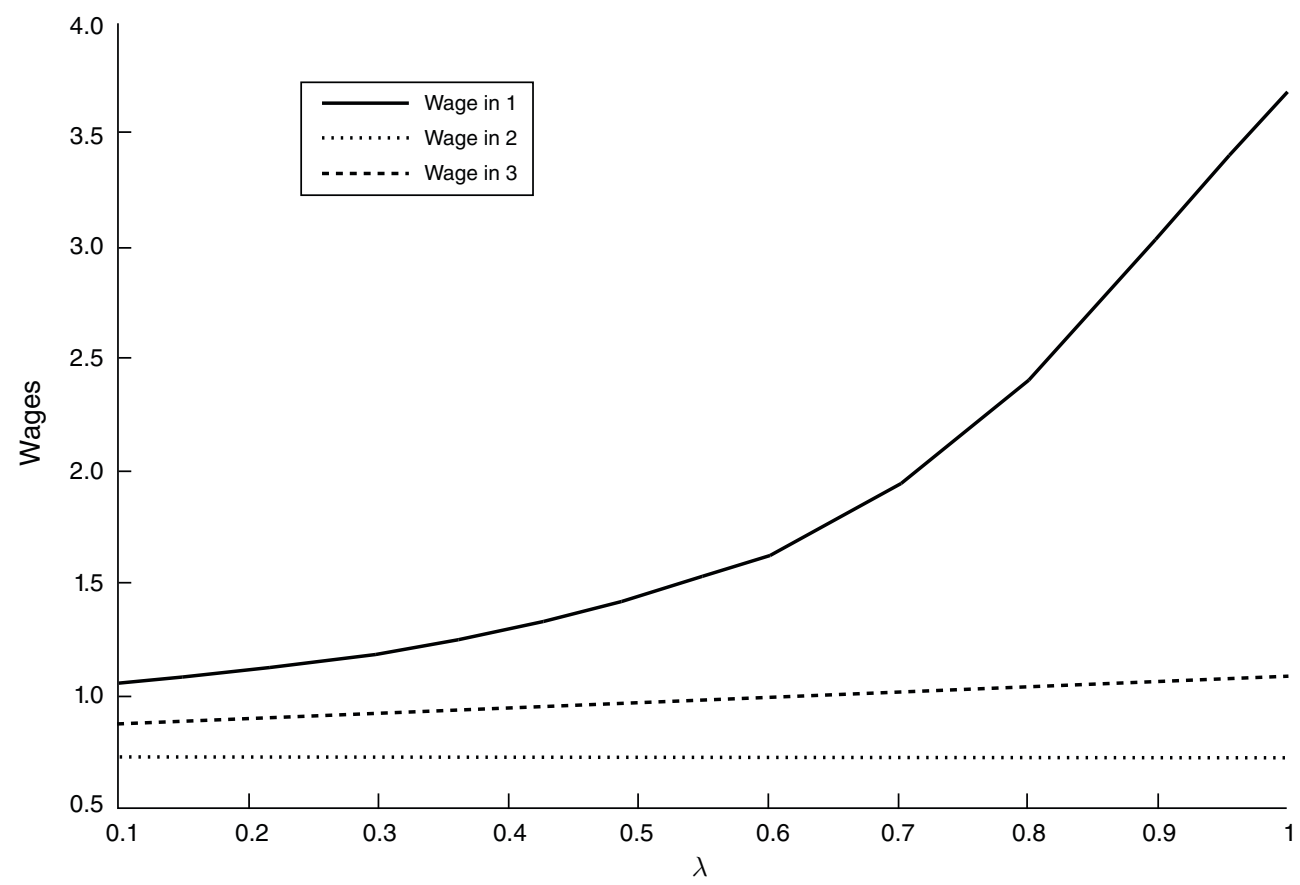

Figure 2. Steady-State Wages Against $\lambda$

Note: This simulation uses $\theta=8, \phi_{1} / \phi_{N}=1, \phi_{2} / \phi_{N}=0.04$, and $\phi_{3} / \phi_{N}=0.2$.

from the improvement in world efficiency that arises from increased trade, just as third countries that do not participate at all in offshoring.

The implications of offshoring for rich countries turn out to be closely related to those of immigration. In both cases there is a short-run decline in the TOT and reallocation of resources from production to research that weakens this effect in the long run. But there is a key difference. Whereas workers that export services through offshoring are paid the wages prevailing in poor countries, migrants earn rich-country wages. As a result, rich countries stand to gain more from increased fragmentation and offshoring than from immigration.

Coming back to the effects of offshoring, the presence of opposite short- and longrun effects implies that the net effect of increased fragmentation for intertemporal utility in the rich country could be positive or negative. This depends on the speed with which resources can be reallocated across production and research. If this is sufficiently fast, then the long-run effects dominate and the rich country gains from offshoring. More generally, if there is a gradual process of increasing fragmentation, the rich country gains as long as the intersectoral reallocation of resources is not too sluggish relative to the pace at which fragmentation is increasing.

It is clear that TOT effects play a key role in the model. At the theoretical level, all that is necessary for such effects to be present is that demand curves be downward sloping. But are TOT effects important in practice? To answer this question, Daron Acemoglu and Jaume Ventura (2002) ran a cross-country regression of the 
change in the TOT against growth. To focus on capital accumulation rather than improvements in productivity (which could improve TOT through other channels), they instrument growth by the catch-up or conditional convergence component of growth derived from a standard cross-country growth regression. They find that faster growth is associated with a stronger deterioration of a country's TOT. On the other hand, David Hummels and Peter J. Klenow (2005) show that larger countries do not exhibit lower prices for their exports. This comes out of a cross-country regression of export prices on size, measured by total employment, while controlling for income levels. According to the Eaton and Kortum (2002) model, however, an increase in size — ceteris paribus - should lead to a declining income level as the country's TOT deteriorates. When the income level is held constant in the regression, some positive force must be compensating for this negative size effect (see Hummels and Klenow 2005, footnote 4). The possibility suggested by Hummels and Klenow (2005) is that larger countries export a larger variety of goods. In the model presented in this paper, there is an expansion in the set of goods exported due to an improvement in the level of technology brought about by an increase in research. As a result, export prices are not lower for larger countries in steady state. 35

Another implication of the model is that fragmentation and increased offshoring lead to an increase in productivity. It seems very reasonable to think that the increase in offshoring has been a conscious decision on the part of firms to lower costs, and that this would be reflected in an increase in productivity. Recent research is consistent with this expectation. Mary Amiti and Shang-Jin Wei (2006) show that US industries with stronger expansions in offshoring of services have experienced higher productivity growth; the evidence is positive but weaker for materials offshoring. Holger Görg, Aoife Hanley, and Eric Strobl (2008) and Alexander Hijzen, Tomohiko Inui, and Yasuyuki Todo (2006) find similar results for plant-level data in Ireland and firm-level data in Japan, respectively.

It is more difficult to find direct evidence regarding another of the implications of the model, namely the reallocation of labor from production to research as a consequence of increased offshoring. There has been an increase in the share of workers employed as researchers in the United States and in most rich countries, but this is part of a long-run trend, so it is difficult to attribute it to offshoring (see Jones 2002). Similarly, there is an increase in the share of people employed in nonroutine activities (see David H. Autor, Frank Levy, and Richard J. Murnane 2003) and in nonproduction or skilled occupations (see Feenstra and Hanson 1999). This could be broadly interpreted as an increase in research employment, but clearly this is only indirectly connected to the implications of the model. More research is needed to establish a close and direct link between offshoring and increased research in rich countries.

Blinder (2007) has expressed concerns that the future increase of offshoring in services will generate large costs for the United States during a prolonged transition. One way to interpret this concern in light of the model presented here is that the

\footnotetext{
${ }^{35}$ Note also that, if we think of each industry as a continuum of goods over which countries differ in productivity, then the Eaton and Kortum (2002) model implies no effect of size on export prices (even in the short run). All the effect is absorbed by a change in the country's share of goods exported within each industry.
} 
process of deepening fragmentation will be too fast in relation to the country's ability to reallocate resources from production to research. Levy and Murnane (2006, 13) express a similar concern when they say that "the demand side can change much more rapidly than people can change their skills." The model suggests one way to prevent these transitory costs: by imposing an optimal tariff or export tax the rich country would eliminate the possibility that increased fragmentation and offshoring harms the rich country even in the short run. Of course, such a policy presents many potential dangers, so a better (but more difficult) approach would be to pursue policies to facilitate the reallocation of people from production to research, or from simple tradable tasks to the development of "new processes, new products, and entirely new industries" (Blinder 2007, 28). Levy and Murname (2006) discuss the changes in the education system that would be needed to acomplish this.

A final issue worth discussing concerns the result that fragmentation does not directly benefit the poor countries engaged in offshoring in the long run. This seems inconsistent with the impression of large gains from increasing service exports by some poor countries, particularly India. It could be argued that, as in the model, these are merely short-run gains that will dissipate in the long run, but this seems unlikely. One explanation for long-run gains is the existence of knowledge spillovers triggered by offshoring. The modeling of such spillovers and the estimation of their quantitative importance is certainly an important issue for future research $\frac{\sqrt[36]{6}}{6}$ Alternatively, India's current prosperity could be seen as resulting from its innovative provision of services that permit firms in rich countries to fragment and offshore part of their production process. According to this view, the increase in $\beta$ that causes increased offshoring in the model above is actually the result of innovations by Indian firms. Such firms would then capture some of the productivity gains that, in this paper, have been assumed to go entirely to rich countries. This too seems a worthwile topic for further exploration.

\section{REFERENCES}

Acemoglu, Daron, and Jaume Ventura. 2002. "The World Income Distribution.” Quarterly Journal of Economics, 117(2): 659-94.

Alvarez, Fernando, and Robert E. Lucas. 2005. "General Equilibrium Analysis of the Eaton-Kortum Model of International Trade." National Bureau of Economic Research Working Paper 11764.

Amiti, Mary, and Shang-Jin Wei. 2006. "Service Offshoring and Productivity: Evidence from the United States." National Bureau of Economic Research Working Paper 11926.

-Autor, David H., Frank Levy, and Richard J. Murnane. 2003. "The Skill Content of Recent Technological Change: An Empirical Exploration." Quarterly Journal of Economics, 118(4): 1279-1334.

-Baily, Martin Neil, and Robert Z. Lawrence. 2004. "What Happened to the Great US Job Machine? The Role of Trade and Electronic Offshoring." Brookings Papers on Economic Activity, (2): 21170.

Baldwin, Richard. 2006. "Globalisation: The Great Unbundling(s)." In Globalisation Challenges for Europe, Secretariat of the Economic Council, Finnish Prime Minister's Office, Helsinki.

Baldwin, Richard, and Frédéric Robert-Nicoud. 2007. "Offshoring: General Equilibrium Effects on Wages, Production and Trade.” National Bureau of Economic Research Working Paper 12991.

- Bhagwati, Jagdish. 1958. "Immiserizing Growth: A Geometrical Note." Review of Economic Studies, 25(3): 201-205.

\footnotetext{
${ }^{36}$ See Daniel Trefler (2005) for a broad discussion of this issue in the context of service offshoring.
} 
- Bhagwati, Jagdish, Arvind Panagariya, and T. N. Srinivasan. 2004. "The Muddles over Offshoring." Journal of Economic Perspectives, 18(4): 93-114.

Blinder, Alan S. 2006. “Offshoring: The Next Industrial Revolution?" Foreign Affairs, 85(2): 113-28.

Blinder, Alan S. 2007. "Offshoring: Big Deal, or Business as Usual?” Unpublished.

Cairncross, Frances. 1997. The Death of Distance: How the Communications Revolution is Changing Our Lives. Boston: Harvard Business School Press.

Davis, Don R., and David E. Weinstein. 2002. "Technological Superiority and the Losses from Migration." National Bureau of Economic Research Working Paper 8971.

Deardorff, Alan V. 2001. "Fragmentation in Simple Trade Models." North American Journal of Economics and Finance, 12(2): 121-37.

Deardorff, Alan V. 2004. "A Trade Theorist's Take on Skilled-Labor Outsourcing.” Research Seminar in International Economics, University of Michigan Working Paper 519.

Deardorff, Alan V. 2005. "Gains from Trade and Fragmentation.” Research Seminar in International Economics, University of Michigan Working Paper 543.

-Eaton, Jonathan, and Samuel Kortum. 2001. "Technology, Trade, and Growth: A Unified Framework." European Economic Review, 45(4-6): 742-55.

-Eaton, Jonathan, and Samuel Kortum. 2002. “Technology, Geography, and Trade.” Econometrica, 70(5): 1741-79.

Ernst, Dieter. 2006. Innovation Offshoring: Asia's Emerging Role in Global Innovation Networks. Honolulu, Hawaii: East-West Center.

Feenstra, Robert C., and Gordon H. Hanson. 1996. "Foreign Investment, Outsourcing and Relative Wages." In The Political Economy of Trade Policy: Papers in Honor of Jagdish Bhagwati, ed. Robert C. Feenstra, Gene M. Grossman, and Douglas A. Irwin, 89-127. Cambridge, MA: MIT Press.

Feenstra, Robert C., and Gordon H. Hanson. 1999. "The Impact of Outsourcing and High-Technology Capital on Wages: Estimates for the United States, 1979-1990." Quarterly Journal of Economics, 114(3): 907-40.

- Fifarek, Brian J., Francisco Veloso, and Cliff I. Davidson. 2008. "Offshoring Technology Innovation: A Case Study of Rare Earth Technology.” Journal of Operations Management, 26(2): 222-38.

Friedman, Thomas L. 2005. The World is Flat: A Brief History of the Twenty-first Century. New York: Farrar, Straus and Giroux.

- Glass, Amy Jocelyn, and Kamal Saggi. 2001. "Innovation and Wage Effects of International Outsourcing." European Economic Review, 45(1): 67-86.

-Görg, Holger, Aoife Hanley, and Eric Strobl. 2008. "Symposium on Firm-Level Adjustment to Globalization: Productivity Effects of International Outsourcing: Evidence from Plant Level Data." Canadian Journal of Economics, 41(2): 670-88.

Grossman, Gene M., and Elhanan Helpman. 1991. Innovation and Growth in the Global Economy. Cambridge, MA: MIT Press.

Grossman, Gene M., and Esteban Rossi-Hansberg. 2006. "The Rise of Offshoring: It's Not Wine for Cloth Anymore." In The New Economic Geography: Effects and Policy Implications, Jackson Hole Conference Volume, Federal Reserve Bank of Kansas. http://www.kc.frb.org/publicat/ sympos/2006/PDF/8GrossmanandRossi-Hansberg.pdf.

-Grossman, Gene M., and Esteban Rossi-Hansberg. 2008. "Trade in Tasks: A Simple Theory of Offshoring." American Economic Review, 98(5): 1978-97.

Hijzen, Alexander, Tomohiko Inui, and Yasuyuki Todo. 2006. "Does Offshoring Pay? Firm-Level Evidence from Japan." Research Institute of Economy, Trade and Industry Discussion Paper Series 07-E-005.

Hira, Ron, and Anil Hira. 2005. Outsourcing America: What's Behind Our National Crisis And How We Can Reclaim American Jobs. New York: AMACOM.

- Hummels, David, and Peter J. Klenow. 2005. “The Variety and Quality of a Nation's Exports.” American Economic Review, 95(3): 704-23.

-Jones, Charles I. 2002. "Sources of U.S. Economic Growth in a World of Ideas." American Economic Review, 92(1): 220-39.

-Jones, Ronald. 2005. "Immigration vs Outsourcing: Effects on Labor Markets." International Review of Economics \& Finance, 14(2): 105-114.

Jones, Ronald W., and Henryk Kierzkowski. 1990. "The Role of Services in Production and International Trade: a Theoretical Framework." In The Political Economy of International Trade, ed. Ronald W. Jones and Anne O. Krueger, 31-48. Oxford: Blackwell.

Jones, Ronald W., and Henryk Kierzkowski. 2001. "Globalization and the Consequences of International Fragmentation." In Money, Capital Mobility and Trade: Essays in Honor of Robert A. 
Mundell, ed. Guillermo A. Calvo, Rudi Dornbusch, and Maurice Obstfeld, 365-384. Cambridge, MA: The MIT Press.

Klein, Paul, and Gustavo J. Ventura. 2007. "TFP Differences and the Aggregate Effects of Labor Mobility in the Long Run." B.E. Journal of Macroeconomics, 7(1).

-Kohler, Willhelm. 2004. "International Outsourcing and Factor Prices with Multistage Production." Economic Journal, 114(494): C166-85.

-Kortum, Sam S. 1997. "Research, Patenting, and Technological Change." Econometrica, 65(6): 13891419.

-Krugman, Paul R., and Anthony J. Venables. 1995. "Globalization and the Inequality of Nations." Quarterly Journal of Economics, 110(4): 857-80.

-Leamer, Edward E. 2007. "A Flat World, A Level Playing Field, a Small World After All, or None of the Above? A Review of Thomas L. Friedman's The World is Flat." Journal of Economic Literature, 45(1): 83-126.

Levy, Frank, and Richard J. Murnane. 2006. "How Computerized Work and Globalization Shape Human Skill Demands." In Learning in the Global Era: International Perspectives on Globalization and Education, ed. Marcelo M. Suarez Orozco, 158-74. Berkeley: University of California Press.

Macher, Jeffrey T., and David C. Mowery, ed. 2008. Innovation in Global Industries: U.S. Firms Competing in a New World (Collected Studies). Washington, DC: National Academies Press.

Mankiw, N. Gregory, and Phillip Swagel. 2006. "The Politics and Economics of Offshore Outsourcing." National Bureau of Economic Research Working Paper 12398.

Markusen, James. 2005. "Modeling the Offshoring of White-Collar Services: From Comparative Advantage to the New Theories of Trade and Federal Direct Investment." In Brookings Trade Forum 2005: Offshoring White-Collar Work, ed. Lael Brainard and Susan M. Collins, 1-34. Washington, DC: The Brookings Institution.

Mitra, Devashish, and Priya Ranjan. 2009. "Offshoring and Unemployment: The Role of Search Frictions and Labor Mobility." Unpublished.

-Naghavi, Alireza, and Gianmarco Ottaviano. 2009. "Offshoring and Product Innovation.” Economic Theory, 38(3): 517-32.

Ottaviano, Gianmarco I. P., and Giovanni Peri. 2006. "Rethinking the Effects of Immigration on Wages." National Bureau of Economic Research Working Paper 12497.

Robert-Nicoud, Frédéric. 2008. "Offshoring of Routine Tasks and (de)industrialisation: Threat or Opportunity-And for whom?" Journal of Urban Economics, 63(2): 517-35.

Roberts, Paul Craig. 2004. "Guest Commentary: The Harsh Truth About Outsourcing." BusinessWeek, March 22. http://www.businessweek.com/magazine/content/04_12/b3875614.htm.

-Samuelson, Paul A. 2004. "Where Ricardo and Mill Rebut and Confirm Arguments of Mainstream Economists Supporting Globalization.” Journal of Economic Perspectives, 18(3): 135-46.

Trefler, Daniel. 2005. "Service Offshoring: Threats and Opportunities." In Brookings Trade Forum 2005: Offshoring White-Collar Work, ed. Lael Brainard and Susan M. Collins, 35-60. Washington, DC: Brookings Institution Press.

-Yi, Kei-Mu. 2003. "Can Vertical Specialization Explain the Growth of World Trade?" Journal of Political Economy, 111(1): 52-102. 


\section{This article has been cited by:}

1. Wanida Ngienthi, Fumio Dei. 2012. The Impact of Differential Falls in Offshoring Costs on Welfare. Review of International Economics 20:1, 72-80. [CrossRef]

2. Rosario Crinò. 2011. Service Offshoring and the Skill Composition of Labour Demand*. Oxford Bulletin of Economics and Statistics no-no. [CrossRef] 